

\title{
THERMAL ABSORPTION IN SEEDED GASES
}

\section{by Valerie C. Burkig}

\section{Prepared by}

DOUGLAS AIRCRAFT COMPANY, INC.

Santa Monica, Calif.

for

NATIONAL AERONAUTICS AND SPACE ADMINISTRATION - WASHINGTON, D. C. • JUNE 1967 
NASA CR-811

THERMAL ABSORPTION IN SEEDED GASES

By Valerie C. Burkig

Distribution of this report is provided in the interest of information exchange. Responsibility for the contents resides in the author or organization that prepared it.

Issued by Originator as DAC-59985

Prepared under Contract No. NASw-1310 by

DOUGLAS AIRCRAFT COMPANY, INC.

Santa Monica, Calif.

for

NATIONAL AERONAUTICS AND SPACE ADMINISTRATION

For sale by the Clearinghouse for Federal Scientific and Technical Information

Springfield, Virginia 22151 - CFSTI price $\$ 3.00$ 


\section{SUMMARY}

An experimental determination was made of the temperatures achieved when a solid particle dispersion in helium and hydrogen was exposed to radiant energy from a high power xenon flashtube. Micron size particles of carbon, iron, and tantalum carbide were employed, and temperature was determined from observation of pressure rise at constant volume. Experiments were aimed at obtaining maximum temperature rise and observing physical or chemical changes in the gas particle dispersion at elevated temperature.

A theoretical model was devised closely simulating the experiment and from it particle and gas temperatures were predicted as a function particle size, particle density, and heat transfer from the particle by radiation and conduction. Peak temperatures are higher and occur earlier in time in helium than in hydrogen because of the lower specific heat in helium.

Hydrogen with a $\mathrm{TaC}$ seed approaches the predicted value although some loss of absorption (or decrease in energy transfer from seed to gas) causes the maximum to occur somewhat earlier and lower than predicted. Helium values fall further short of the predicted temperature peaks in spite of the fact that higher temperatures are reached with helium.

Most of the temperature measurements were made for initial gas pressure of 5 atmospheres and 400 calories of radiant energy measured at the inner surface of the absorption cell. Tantalum carbide particles produced the highest indicated temperatures which for these conditions were $4000^{\circ} \mathrm{K}$ in helium and $2500^{\circ} \mathrm{K}$ in hydrogen. With initial pressure reduced to 2 atmospheres, the same flash lamp energy resulted in indicated temperatures of $5400^{\circ} \mathrm{K}$ in helium and $3900^{\circ} \mathrm{K}$ in hydrogen.

The flash lamp energy was monitored as a function of time and the integral of this signal compared with the observed pressure rise within the absorption cell. A substantial divergence between these two quantities was observed with increasing time indicating a decrease in the ability of the gas particle dispersion to absorb energy. Several independent measurements of optical transmission of the gas particle dispersion were during the flash heating process. None of these indicated any significant variation in optical transmission. Several phenomena which support these observation are considered, but a satisfactory explanation is not yet at hand. 


\section{INTRODUCTION}

In current concepts of the gaseous core reactor for propulsion, the propellant and the fissioning fuel remain separated. Energy transfer is primarily by radiation at wavelengths in the visible and ultraviolet. Since the most likely propellants are transparent to such radiation except at very high temperatures, seeding with small absorbing particles offers a possible means of heating the gas.

Some investigations with seeded gases and liquids have been carried out by several groups. Lanzo and Ragsdale (Reference 1) investigated experimentally the absorption of suspended particles as a function of material, size and concentration; and (Reference 2) investigated heat transfer from an arc to a flowing seeded gas at modest temperatures. Masser (Reference 3) made an analytical study of radiant heating of a seeded gas, as suming constant absorption, for a particular reactor configuration. McAlister et al (Reference 4) have reported on theoretical and experimental studies of radiant heat transfer from a cylindrical enclosure to a cloud within it. Experimentally they endeavored to avoid conduction and convection, and measured the heat gained by the cloud. Results were in good agreement with theory. But none of these has been able to observe phenomena at elevated temperatures. The present work was designed to fill that gap.

In this experiment a cloud of particles in a gas was injected into a transparent quartz tube and exposed to the $2 \mathrm{msec}$ flash of a xenon flashtube having an average power output equivalent to that of a $9000^{\circ} \mathrm{K}$ blackbody. The temperature rise of the gas was inferred from the pressure rise measured with a fast response pressure transducer. The bulk of the work was done with fine particles (about $1 \mu$ ) of carbon, iron, and tantalum carbide. And, in general, initial pressures of 2 and 5 atmospheres were investigated for both helium and hydrogen.

Additional information was obtained by measuring optical transmission through the cloud before and during the flash and by observing the light emitted by the hot gas. Gaseous and solid residues were examined for chemical products and evidence of vaporization. The integrated energy a vailable inside the absorption cell from a single flash was determined by observing the temperature rise in a graphite rod placed inside the cell. The power curve was found by following the light pulse with a silicon photodiode.

In this experimental arrangement the available power input to the absorption cell was very high $\left(12,000\right.$ watts $/ \mathrm{cm}^{2}$ average) and, although less than 50 percent of it was absorbed, the seed temperature rose rapidly, with the 
gas temperature following. The lamp power dropped rapidly after its peak so that near the end of the pulse the gas temperature exceeded the source temperature. Particle reradiation is, at this point, an important effect.

It is probable that changes in the particles occurred during heating: the emissivity could change with melting or evaporation; particle size could change with agglomeration or with partial evaporation; and gas thermal conductivity could be changed in the immediate neighborhood of the particle surface. But the occurrence of such changes has not been definitely established by experiments.

An analytic model was constructed to describe the behavior of a unit cell consisting of a sphere of gas surrounding a solid particle absorber. Thermal radiation is then absorbed at the particle surface which is allowed to reradiate to a sink at absolute zero. Heat from the particle surface is transferred by conduction to the surrounding gas with no loss of energy at the surface of the sphere. This model provides a small scale description of an idealized unit cell, but is inadequate to treat the larger scale behavior of conductive cooling of the total mass of gas within the absorption cell. An existing heat transfer program, JA56, was used to treat this part of the problem.

\section{Analytical Work}

An existing computer code, Douglas JA 56, was used for a portion of the absorption cell temperature analysis. This program has many advantages. The region of interest can be divided into a large number of volume elements or nodes. Source terms and temperature dependent material properties are fed in as tables. The program can follow the heating (or cooling) of each node adjusting for temperature dependent specific heat and thermal conductivity and taking into account conduction across interfaces. Convection and radiation can also be computed if suitable coefficients are inserted into the program.

However, the material within a node is assumed to be homogeneous. There is no provision for treating particles at a different temperature from the surrounding gas.

To simulate the heating portion of this experiment it was felt that the seed and gas must be treated individually. Therefore, it was decided to use JA56 only to compute conductive cooling of the gas after the source was switch off.

The first part of the analysis deals with heating of the seed and gas. Only radiative cooling is considered. Conduction losses from the gas are considered in the second section.

The heating of a seeded gas occurs in two steps; the absorption of radiant energy by the particles and the conduction of heat from the particles to the gas. 
If a spherical particle of radius " $a$ " is enclosed in a spherical gas volume of radius " $r_{0}$ " in an isotropic radiation field the temperature history of the particle is given by:

$$
{ }_{3}^{4} \pi a^{3} \rho \frac{C}{M} \frac{d T}{d \theta}=4 \pi a^{2} \epsilon \phi(\theta)-4 \pi a^{2} \epsilon \sigma T^{4}-4 \pi a^{2} \phi_{g}
$$

or

$$
\frac{d T}{d \theta}=\frac{3 M}{\rho C a}\left[\epsilon \sigma\left(\frac{\phi(\theta)}{\sigma}-T^{4}\right)-\phi_{g}(\theta)\right]
$$

where

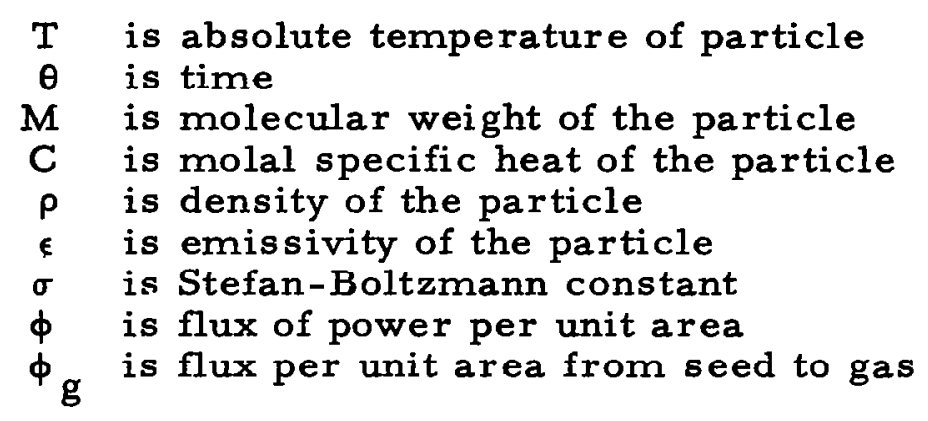

The temperature history of the gas, for an adiabatic boundary at $\mathbf{r}_{0}$, is given by,

$$
\frac{4}{3} \pi r_{0}^{3} \frac{\rho_{g} C_{g}}{M_{g}} \frac{d T_{g}}{d \theta}=4 \pi a^{2} \phi_{g}
$$

where

$$
\begin{aligned}
T_{g} & =\text { spatial average temperature of gas } \\
P_{G} & =\text { density of gas } \\
C_{g} & =\text { molal specific heat of gas } \\
M_{\mathbf{g}} & =\text { molecular weight of gas }
\end{aligned}
$$
For a stationary state, the is $\frac{\mathrm{dT}_{\mathrm{g}}}{\text { is determined by the relation: } \mathrm{d \theta}}$ constant, the temperature profile in the gas

$$
-4 \pi r^{2} K \frac{d T}{d r}=\frac{d T g}{d \theta} \times \frac{\rho_{g} C_{g}}{M_{g}} \times \frac{4}{3} \pi\left(r_{o}{ }^{3}-r^{3}\right)
$$

where $K$ is the gas thermal conductivity. 
If the temperature at $r_{0}$, the edge of the unit cell of gas, is $T_{0}$, then a solution of this equation gives:

$$
T-T_{0}=\frac{d T_{g}}{d \theta} \times \frac{\rho_{g} C_{g}}{3 M_{g} K} \times \frac{r_{o}{ }^{3}}{a}
$$

Now the temperature profile defined by equation (2) is very steep in the region near the particle so that the volumetric average temperature $\mathrm{T}_{\mathrm{g}}$ is very nearly equal to $T_{o}$. Setting $T_{o}=T_{g}$ in equation (3), equations (1) and (3) can be solved simultaneously for given initial conditions and specified functional dependence of $\phi(\theta)$. The derivation of equation (3) in which $\frac{d T_{g}}{d \theta}$ was assumed constant may at first seem inconsistent. However, the approximation involved is that the time required to adjust the stationary state temperature profile in the unit cell is short compared to the times over which significant changes in $\frac{d T_{g}}{d \theta}$ take place.

A program was written in which the solution of equations (1) and (3) was performed by the Runge-Kutta method. Basically this involved dividing the time into microsecond intervals, calculating particle heating during one interval followed by conduction to the gas and recalculation of particle temperature. The process was repeated for succeeding time intervals.

The input flux was based on experimental values for intensity vs time of a $3 \mathrm{kv}$ flash and for integrated energy input to the absorption cell. The determination of these values is discussed in the Experimental Work section. Flux values were entered for $100 \mu \mathrm{sec}$ intervals with the computer interpolating linearly to obtain intermediate values.

A "standard" case was calculated using the following numerical values which are applicable to a $\mathrm{TaC}$ seed in 5 atmospheres of helium.

$$
\begin{aligned}
& \left.\begin{array}{rl}
M & =193 \\
\rho & =14.6 \times 10^{3} \mathrm{Kg} / \mathrm{m}^{3} \\
\mathbf{C} & =25 \times 10^{3} \text { joules } / \mathrm{mole}^{\circ} \mathrm{K} \\
\mathbf{a} & =10^{-6} \text { meters }
\end{array}\right\} \text { particle } \\
& \begin{aligned}
\mathrm{M}_{\mathrm{g}} & =4 \mathrm{Kg} \\
\rho_{\mathrm{g}} & =0.9 \mathrm{Kg} / \mathrm{m}^{3} \\
\mathrm{C}_{\mathrm{g}} & =12.5 \times 10^{3} \text { joules } / \mathrm{mole} /{ }^{\circ} \mathrm{K}
\end{aligned} \\
& \mathbf{r}_{\mathrm{o}}=3 \times 10^{-5} \text { meter } \mathrm{s} \\
& \mathrm{K}=0.144 \mathrm{watts} / \text { meter }^{\circ} \mathrm{K} \\
& \epsilon=1 \\
& \sigma=5.67 \times 10^{-8} \frac{\text { watts }}{\mathrm{m}^{20} \mathrm{~K}^{4}}
\end{aligned}
$$

Figure 1 shows the particle and gas temperatures for the standard case compared with the source temperature curve. The latter was calculated from the experimentally determined power input curve by $T_{\text {source }}^{\cdot}=(\phi / \sigma \epsilon)^{1 / 4}$. 


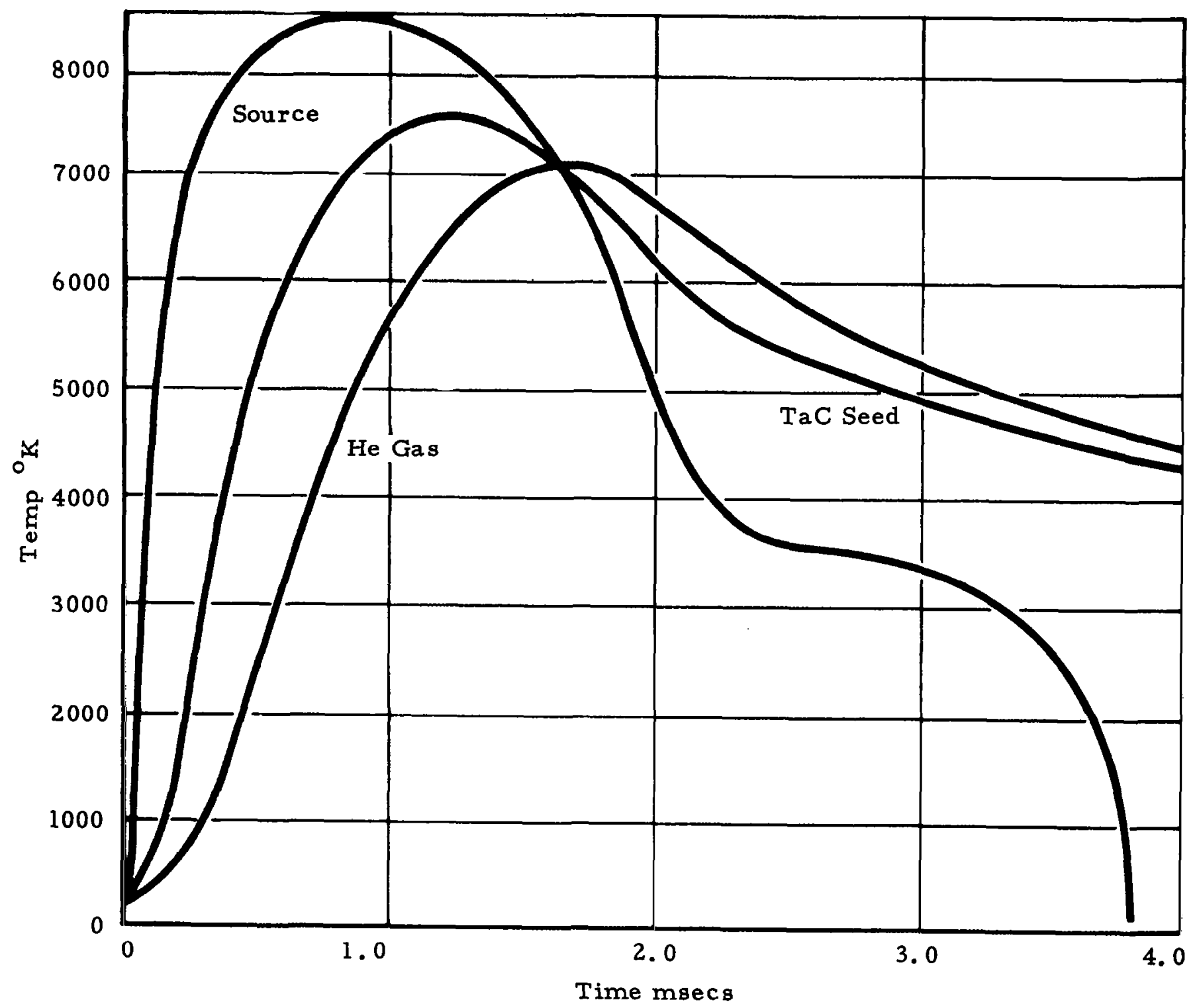

FIGURE 1 PREDICTED GAS AND SEED TEMPERATURES FOR "STANDARD" CASE 
After a rapid fall from about $8000^{\circ} \mathrm{K}$ the source temperature curve shows a $3000^{\circ} \mathrm{K}$ temperature for $1.5 \mathrm{msec}$. This appears as a faint residual glow in the light output curve and may be due to failure to achieve critical damping in the flashtube circuit.

The seed temperature is seen to peak at $7400^{\circ} \mathrm{K}$ at about $1.2 \mathrm{msec}$ while the gas reaches nearly $7000^{\circ} \mathrm{K}$ at about $1.6 \mathrm{msec}$.

Figure 2 shows the effect of decreasing the emissivity (and absorptivity) to $\epsilon=0.5$. Clearly the temperatures reached by both particle and gas are less, the peaks occur later and the radiation cooling is slower.

In Figure 3 the result of decreasing thermal conductivity by a factor of 10 is illustrated. The peak particle temperature is high and occurs at about the same time as the peak source temperature while the peak gas temperature occurs later and is much lower than in the standard case.

Figure 4 illustrates a case with hydrogen instead of helium, other parameters held constant. Gas and particle temperatures are lower than with helium and the gas temperature peak occurs later.

For a system of uniformly distributed spherical particles of radius a, material density $\rho$ and of concentration $C$ (mass/unit volume), the radius of the unit cell associated with each particle is $r_{0}=a^{3} \rho / C$. For the materials used and their estimated concentrations the ratio $r_{0} / a$ was of the order of 30 for each case. This was the ratio used in the "standard" calculation.

Agglomeration or breaking up of the particles would increase or decrease both " $a$ " and " $r_{0}$ " simultaneously. For agglomeration the effect of increased particle size is a small increase in gas temperature but the dominant effect of increased unit cell size results in an actual lowering of the peak gas temperature. Correspondingly the effect of particle breakup is to increase the peak gas temperature.

As the energy input from the flashtube decreases, the radiation from the particles falls off rapidly and conduction to the walls becomes the main mechanism for temperature loss. This loss was calculated using the JA56 program. I he following assumptions were made.

1. The problem was one dimensional and the TaC seed, uniformly distributed. The volume considered was one quarter of a right circular cylinder, 1 inch high, of radius $6.5 \mathrm{~mm}$. This was divided radially into 13 nodes of equal volume, thus the radial depth of the innermost node was considerably greater than those of our nodes.

2. Outside the 13 th node a $3 \mathrm{~mm}$ quartz wall was maintained at $70^{\circ} \mathrm{F}$.

3. Convection and radiation were not treated.

4. The thermal conductivity was taken to be that of the gas only but the specific heat values were those of the combined gas and seed; temperature dependence was included. Hydrogen properties were taken from Grier (Reference 5). 




FIGURE 2 PREDICTED SEED AND GAS TEMPERATURE $\epsilon=.5$ 


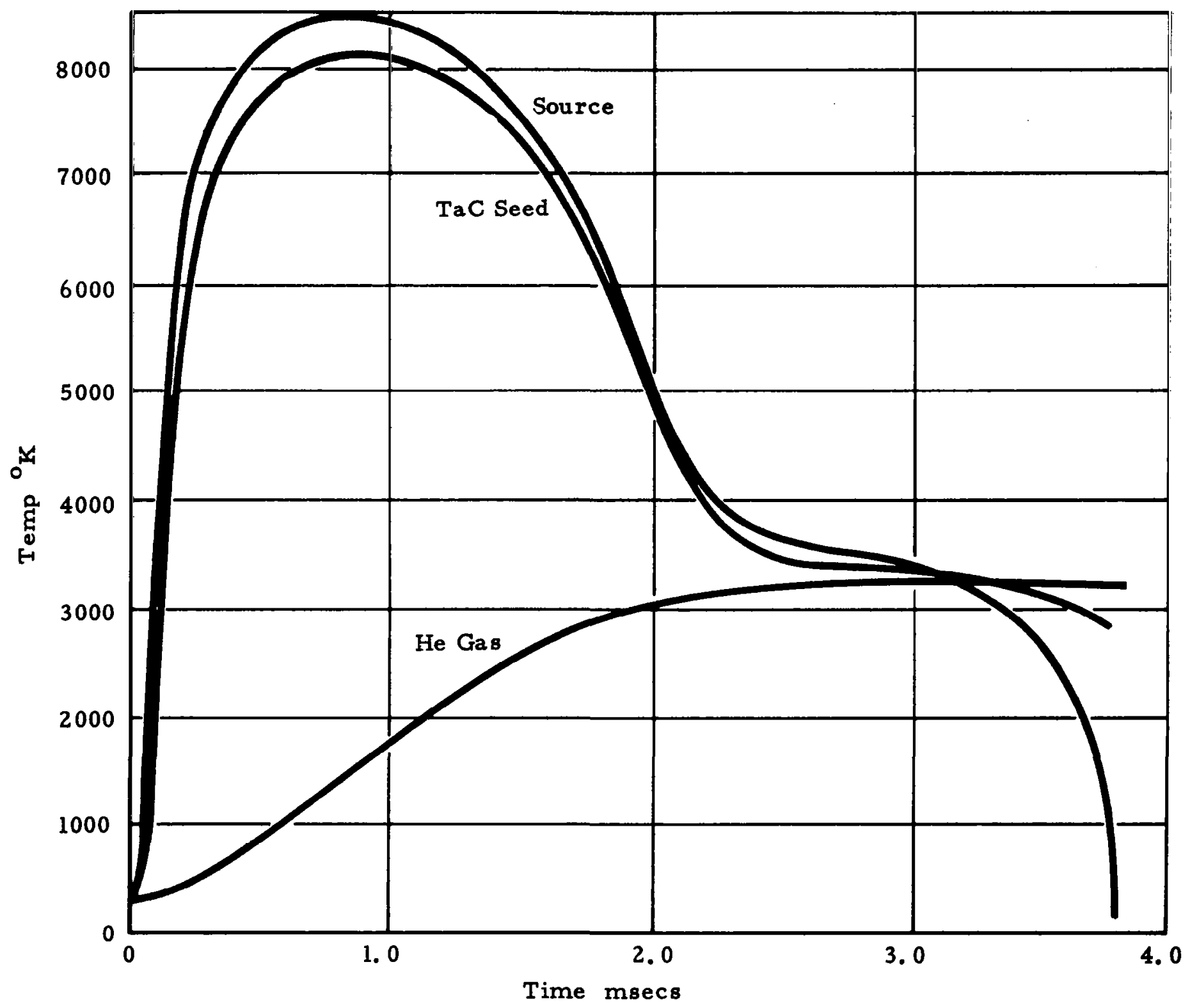




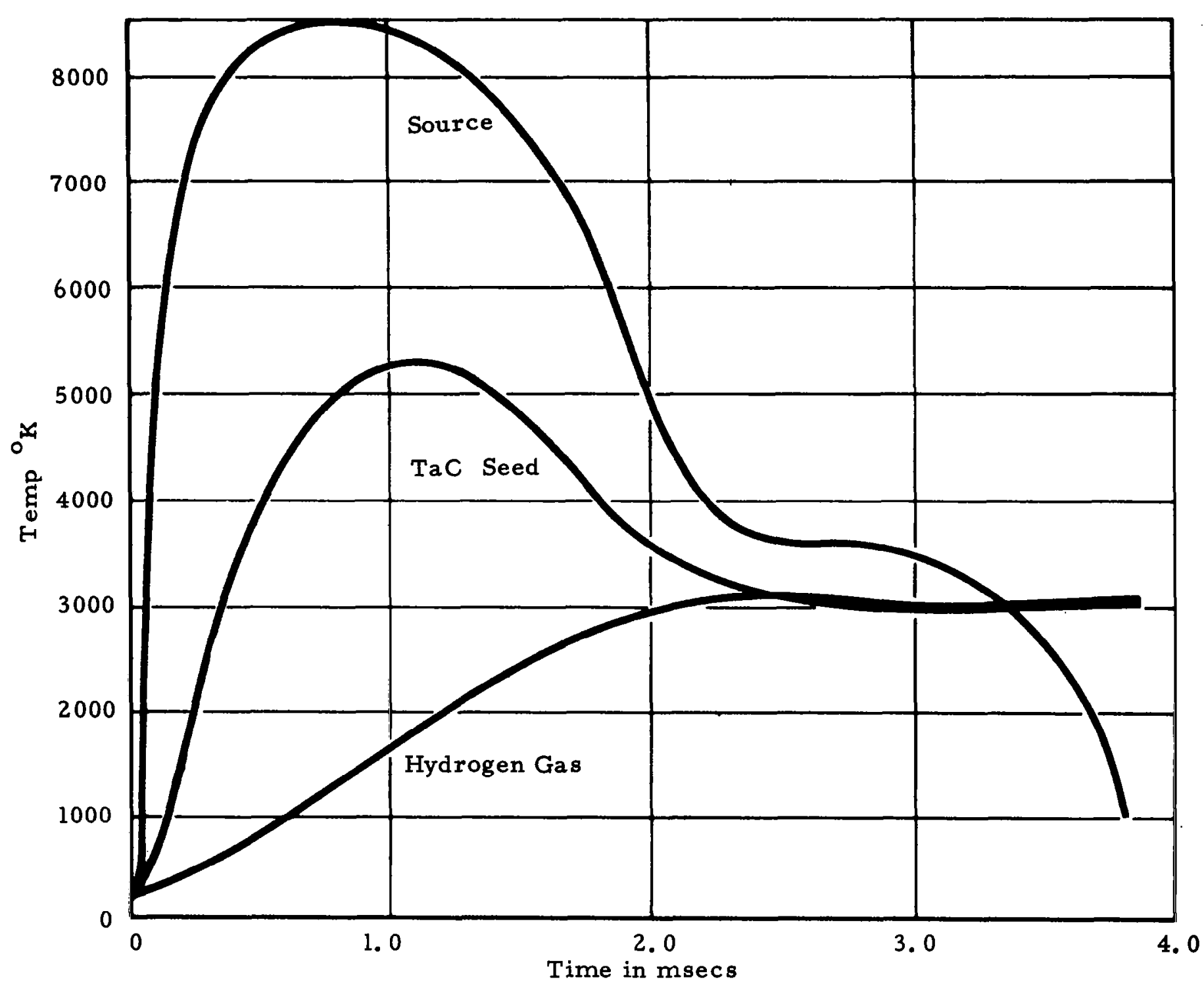

FIGURE 4 PREDICTED GAS AND SEED TEMPERATURES - HYDROGEN 
The conduction cooling curves for helium and hyrogen (Figures 5 and 6) were calculated by the program assuming in each case that all nodes were initially at the same temperature, from $1000^{\circ} \mathrm{K}$ to $7000^{\circ} \mathrm{K}$.

Figure 7 shows the "standard case" gas temperature curve with a helium conduction cooling curve for $4500^{\circ} \mathrm{K}$ fitted to it. And Figure 8 shows the hydrogen heating curve joined to a $3000^{\circ} \mathrm{K}$ hydrogen cooling curve.

No effort has been made to consider convection in these treatments. However when the Grashof Number is calculated for typical cases it is found to be of the order of 3000 for hydrogen and 20,000 for helium. Since a Grashof Number $>2.000$ indicates the probability of convection this effect is not negligible, for helium in particular, and may be responsible for more rapid cooling than predicted.

Experimental Work

High energy xenon flashtubes are used as intense sources of thermal radiation in these experiments. These flashtubes are available both in linear and helical configurations. The helical tubes are characterized by higher breakdown voltage and somewhat lower energy density than linear tubes. These factors along with the more efficient optical coupling combine to make the maximum energy capability nearly the same for the two lamp types. The bulk of the experimental work in this program was carried out with linear lamps in an elliptical cavity. However, some comparative measurements were also made with a helical lamp. The following paragraphs describe the flash lamp assemblies, calorimetric measurements, particle dispersion, and pressure and optical observation of heated gas samples.

Linear Flashtube Assembly. - Following the design of Hronik et al (Reference 6) elliptical ribs were machined and joined together with spacers. A rectangular piece of Alcoa aluminum "lighting sheet" was cut, formed to the elliptical shape and attached to the ribs with an epoxy bead. This produced a highly reflecting elliptic cylinder 6.5 inches high, with an 8.0 inch major axis, 7.6 inch minor axis and 2.5 inches between foci. Reflecting end plates of the same material simulated an infinite cylinder length. The entire assembly was made in two halves which could be separated along the major axis for easy access to the flashtube and absorption cell.

The flashtube, an EG\&G FX-47B with a 6.5 inch arc length was mounted in a C-shaped micarta frame. The 2 inches of each arm nearest to the flashtube were of mycalex to avoid charring during the flash. This form held the flashtube along one focal line of the ellipse. The low eccentricity of the ellipse focused the light in an area only slightly larger than the source, resulting in efficient energy transfer to the cell. 
is

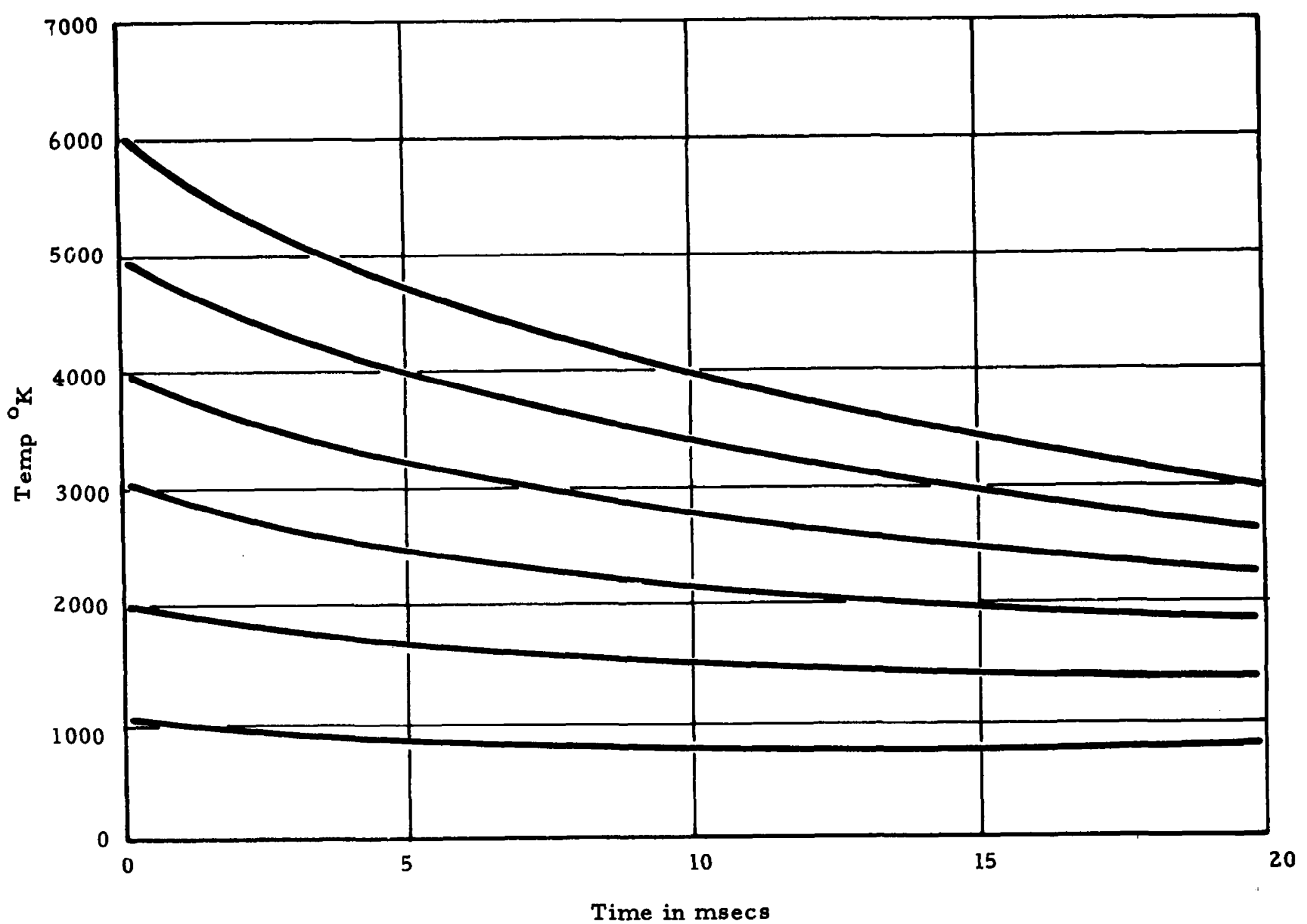

FIGURE 5 PREDICTED CONDUCTION COOLING OF CELL - HELIUM 




FIGURE 6 PREDICTED CONDUCTION COOLING OF CELL - HYDROGEN 
占

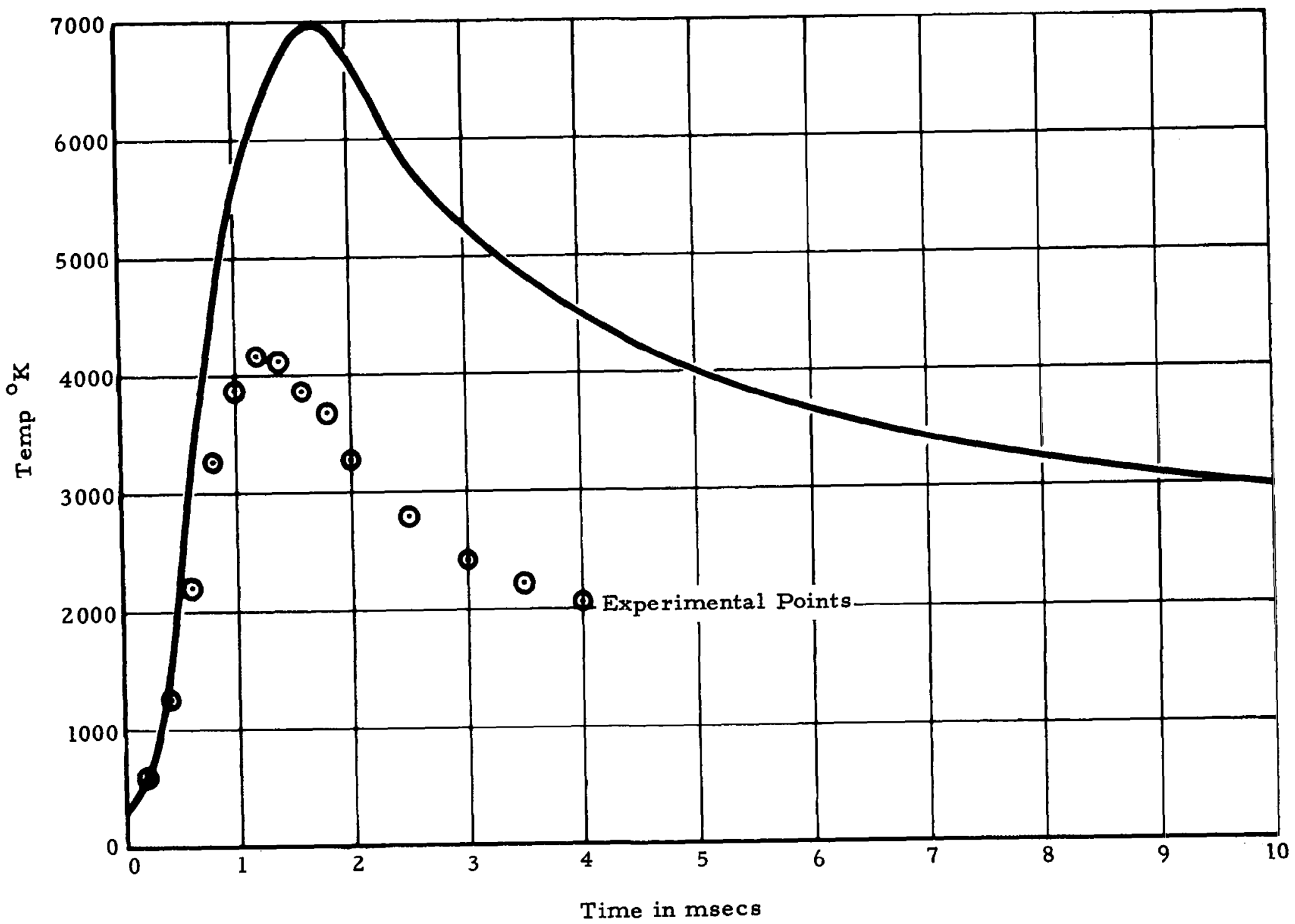

FIGURE 7 PREDICTED GAS TEMPERATURE:

"STANDARD" CASE WITH CONDUCTION 


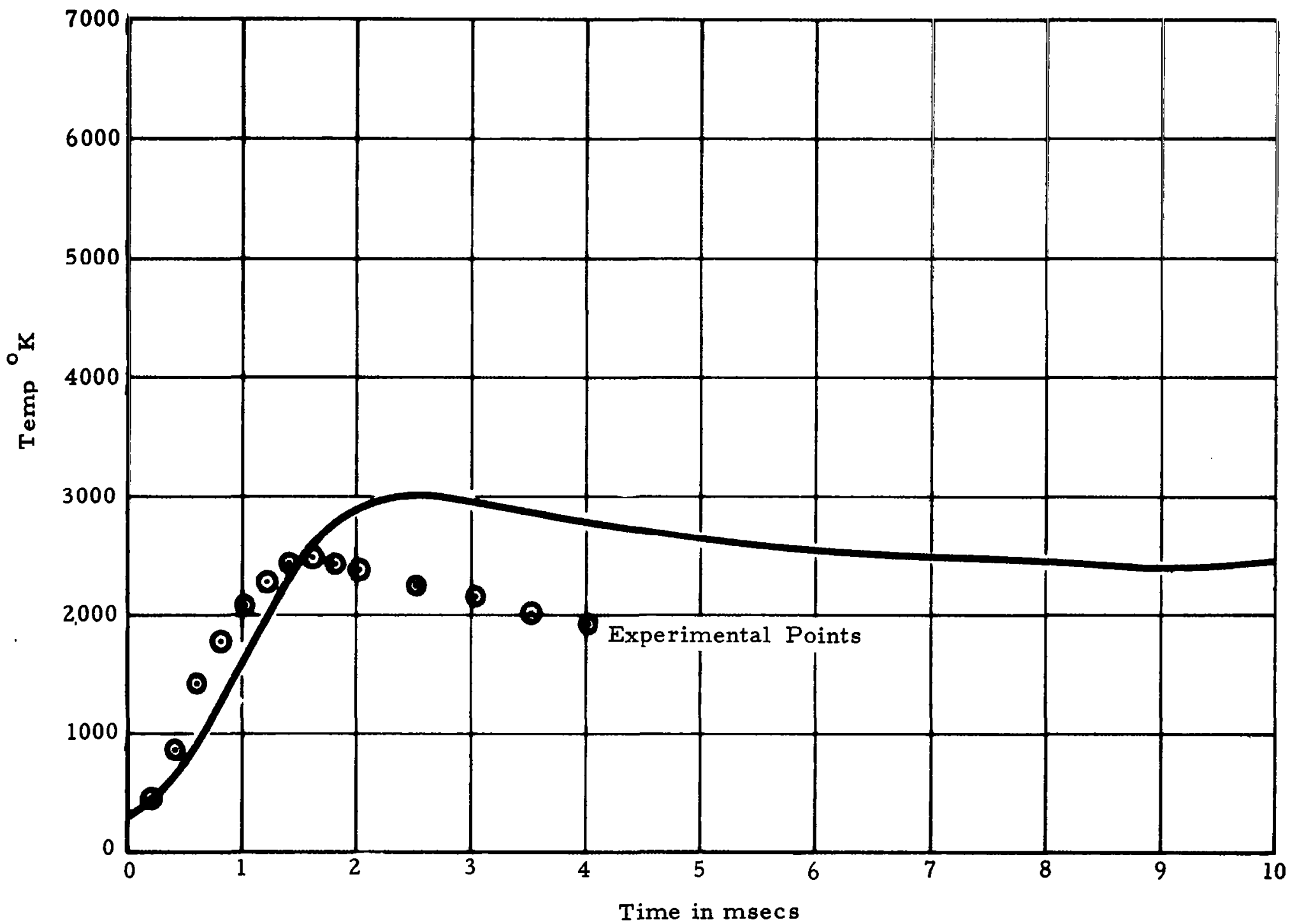

FIGURE 8 PREDICTED GAS TEMPERATURE 
The absorption cell, a 6.5 inch length of quartz tubing of $13 \mathrm{~mm}$ i. d. and $19 \mathrm{~mm}$ o.d., was supported along the other focal line by a heavy triangular frame bolted at the vertices to withstand the pressure pulse. The individual parts were fastened to a micarta base to maintain them in the proper relative positions. A drawing of the assembly is shown in Figure 9.

Both ends of the quartz tube were ground flat and smooth to seal against end 0 -rings. The top 0 -ring groove was cut in a check valve mounted in the triangular frame. The valve opened with an external pressure of more than 1 psi above internal pressure, permitting gas entry, but had positive sealing under internal pressure rise. A needle valve built into the check valve was used to evacuate the cell before admission of the seeded gas. See Figure 10.

A Kistler quartz crystal pressure transducer, used to measure the gas pressure rise, was mounted in the lower triangular frame just at the bottom of the quartz cell. Used with suitable scales on the Charge Amplifier, the transducer could measure from a few pounds to 15,000 psi with a response time of about $10 \mu \mathrm{sec}$. It was necessary to shield the transducer against the light pulse which otherwise registered as a negative pressure due to thermal distortion of the transducer housing.

Flashtube energy was supplied by a $1920 \mu \mathrm{f}$ capacitor bank charged to voltages up to $3 \mathrm{kv}$ and triggered by a $25 \mathrm{kv}$ trigger generator. At higher voltages the tube may fire without application of the trigger voltage. The capacity is limited by the requirement that the discharge energy, $1 / 2 \mathrm{CV}^{2}$, remain below the explosion limit of the tube. Originally the tube was operated in series with an 850 hy choke in accordance with the tube manufacturer's suggested values and the pulse length was about $4 \mathrm{msecs}$. However, this operating point was underdamped producing ringing in the discharge circuit. Reduction of the series inductance to $175 \mu$ hy produced nearly critical damping. Circuit resistance external to the flashtube was held below 2 ohms while the resistance of the FX-47B at full power was about $0.5 \mathrm{ohms}$. The resulting pulse was about $1.5 \mathrm{msec}$ between one third maximum intensity points, and was still safely away from the explosion limit of the tube.

Helical Flashtube Assembly. - The arrangement used with the helical tube was simpler to construct. The absorption cell was placed inside the helix which in turn was surrounded by a cylindrical reflector; both 8-and 5-inch diameter reflectors were tried. The length of the helix, and therefore of the absorption cell and reflector, was 4 inches compared to 6.5 inches for the linear system. By replacing the corner bolts with shorter ones it was possible to use the same triangular frame, with valves and transducers, as was used with the linear tube. 


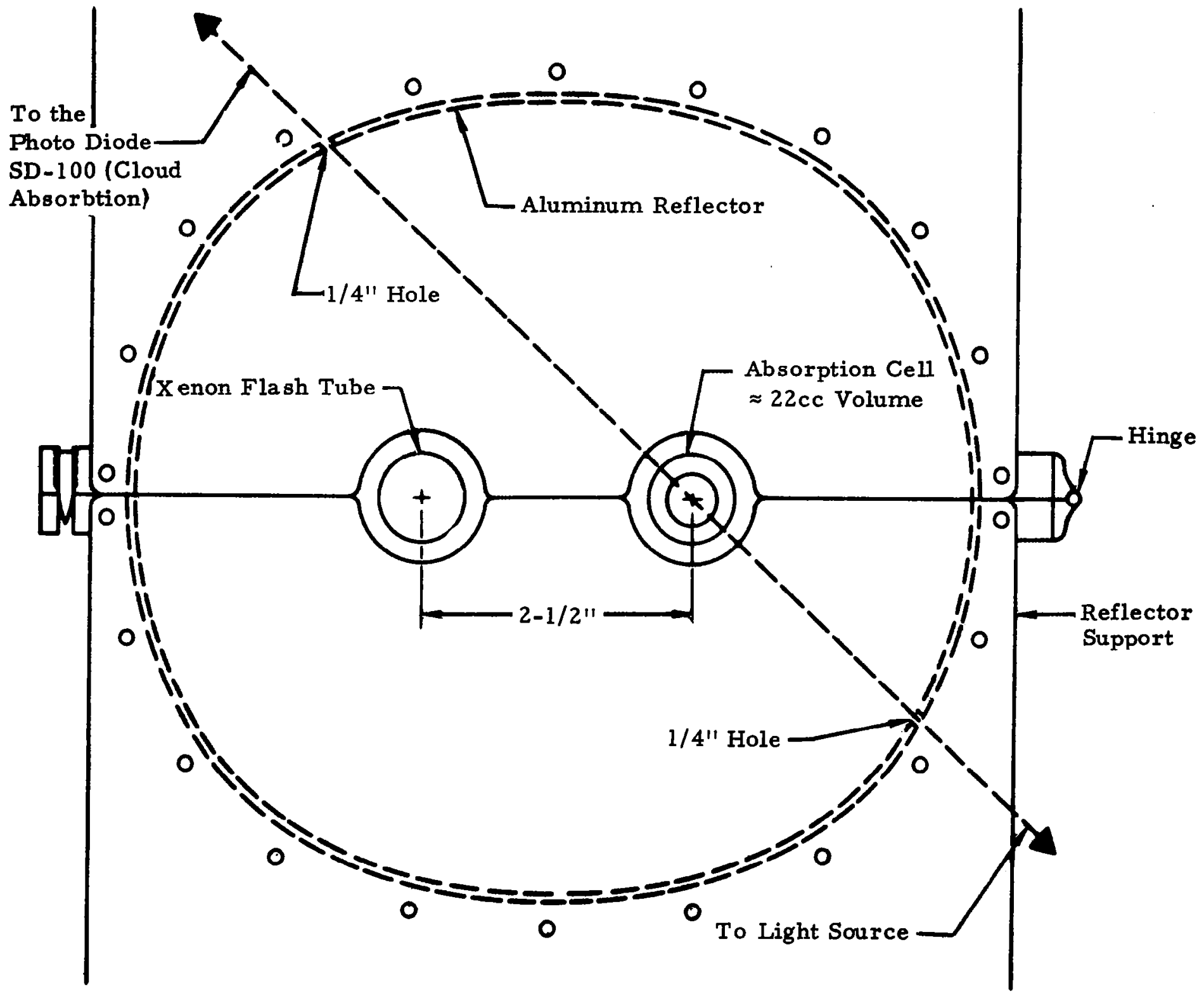

FIGURE 9 DRAWING OF REFLECTOR ASSEMBLY 




FIGURE 10 DRAWING OF ABSORPTION CELL WITH GAS FLOW SYSTEM 
The helical tube (a Kemlite 113-20) has an inherent inductance and can be operated without an external coil. Its time constant was about 5 msec compared to $2 \mathrm{msec}$ for the linear flashtube with 175 hhy choke. The light output pulse showed a rapid rise (about $0.1 \mathrm{msec}$ ), a fairly flat peak for about $1 \mathrm{msec}$, and then a roughly exponential decrease with about a $4 \mathrm{msec}$ time constant. It was estimated that 70 percent of the light output occurred in the first 2 msec.

Graphite Rod Measurements. - While a line source in an elliptical cylinder reflector is focused in a line image, the image of an extended source may be considerably larger than the object depending on the eccentricity of the ellipse and its size compared to that of the object. Schuldt and Aagard (Reference 7) have made a study of the geometrical efficiency of energy transfer from a linear lamp to a laser crystal as a function of laser-to-lamp and ellipse-tolamp dimensions. For the present case the geometrical efficiency was about 75 percent and the image was nearly the same size as the $1 / 2$ inch diameter flashtube. This was checked by measuring the temperature rise in a $3 / 16$ inch diameter graphite rod containing a thermocouple in a hole drilled to the center of the rod. By moving this rod in small increments on successive flashes it was found that the energy was the same within 10 percent over a $1 / 2$ inch diameter area, centered on the focal line, and fell off rapidly outside this area. At a fixed spot, measurements were repeatable to within 1 percent on successive flashes.

A similar type of measurement was used to compare available energy from a single flash each of the linear and helical tubes. For this purpose a $1 / 2$ inch diameter graphite rod was placed inside a $13 \mathrm{~mm}$ quartz absorption cell. Cut to the appropriate 6.5- and 4-inch lengths, the graphite rods essentailly filled the quartz cells used with the two flashtubes. Each rod contained a 28 gauge chromel-alumel thermocouple in a hole drilled to the center of the rod. The thermocouples were pressed into small diameter sections of the holes to assure good contact with the graphite.

The thermocouple output was displayed on an oscilloscope and the peak voltage was converted to temperature using the Chromel-Alumel Thermocouple tables (Reference 8). The energy absorbed by the rod is, of course, the product of graphite rod mass, specific heat and temperature rise. This value was corrected for the surface reflection of graphite electrodes, about 25 percent as measured by Kuebler and Nelson (Reference 9), to give the energy inside the quartz cell available for absorption.

For the helical flashtube, measurements were made with both 8 - and 5 -inch reflector. Table 1 shows a comparison of the two types of flashtubes with the results expressed in energy input/inch to make it possible to compare the two lengths of absorption cell. 
TABLE I

COMPARISON OF HELICAL AND LINEAR SYSTEMS

\begin{tabular}{clcl}
\hline Capacitor Voltage & Tube & Reflector & Energy Input \\
\hline $3 \mathrm{kv}$ & helical & 8 inch circular & 34.5 calories/inch \\
$4 \mathrm{kv}$ & helical & 8 inch circular & 61 \\
$3 \mathrm{kv}$ & helical & 5 inch circular & 42 \\
$3 \mathrm{kv}$ & linear & elliptical & 45 \\
\hline
\end{tabular}

At $3 \mathrm{kv}$ the 5 inch reflector gave about a 20 percent increase in optical coupling over the 8 inch reflector and resulted in roughly the same energy input per inch to the absorption cell as was achieved with the linear flashtube.

Although at $4 \mathrm{kv}$ the helical tube gives the highest energy input, this was not found to be a practical operating condition because of the very short tube life. At $3 \mathrm{kv}$ the helical tube offered no energy advantage over the linear tube. Most of the work was therefore done with the linear tube.

For the linear FX-47B, graphite rod measurements were made at 1. 5, 2.0, 2.5 , and $3.0 \mathrm{kv}$. The values for available energy inside the quartz cell were calculated as described above. The results are plotted in Figure 11 . It is clear that the energy does not increase as $\mathrm{V}^{2}$. This is presumably due to increased circuit resistance and decreased flashtube resistance at higher currents. In that case, a smaller fraction of the energy stored in the capacitors is expended in the flashtube as the applied voltage increases.

The flux of energy into the absorption cell, as a function of time, was determined from the total energy measurement just described combined with information about the shape of the light pulse.

Light Pulse Measurements. - The light pulses were observed with a fast response silicon photodiode (EG\&G SD-100) which is sensitive from wavelengths of about $3000 \mathrm{~A}$ to 1.2 microns with a peak response at about $9000 \mathrm{~A}$. According to the manufacturer this device has a response time of $4 \times 10^{-9}$ seconds and a linear response within 5 percent over 7 orders of magnitude of light intensity. It was set up as shown in Figure 12 and the output voltage displayed on a Tektronix 545 oscilloscope. It was necessary to attenuate the flashtube pulse considerably to avoid overloading the SD-100. This was accomplished by mounting it outside a small hole in the reflector and placing a shield containing only a pinhole over the photodiode. A typical SD- $¥ 00$ output trace is shown in Figure 13. 


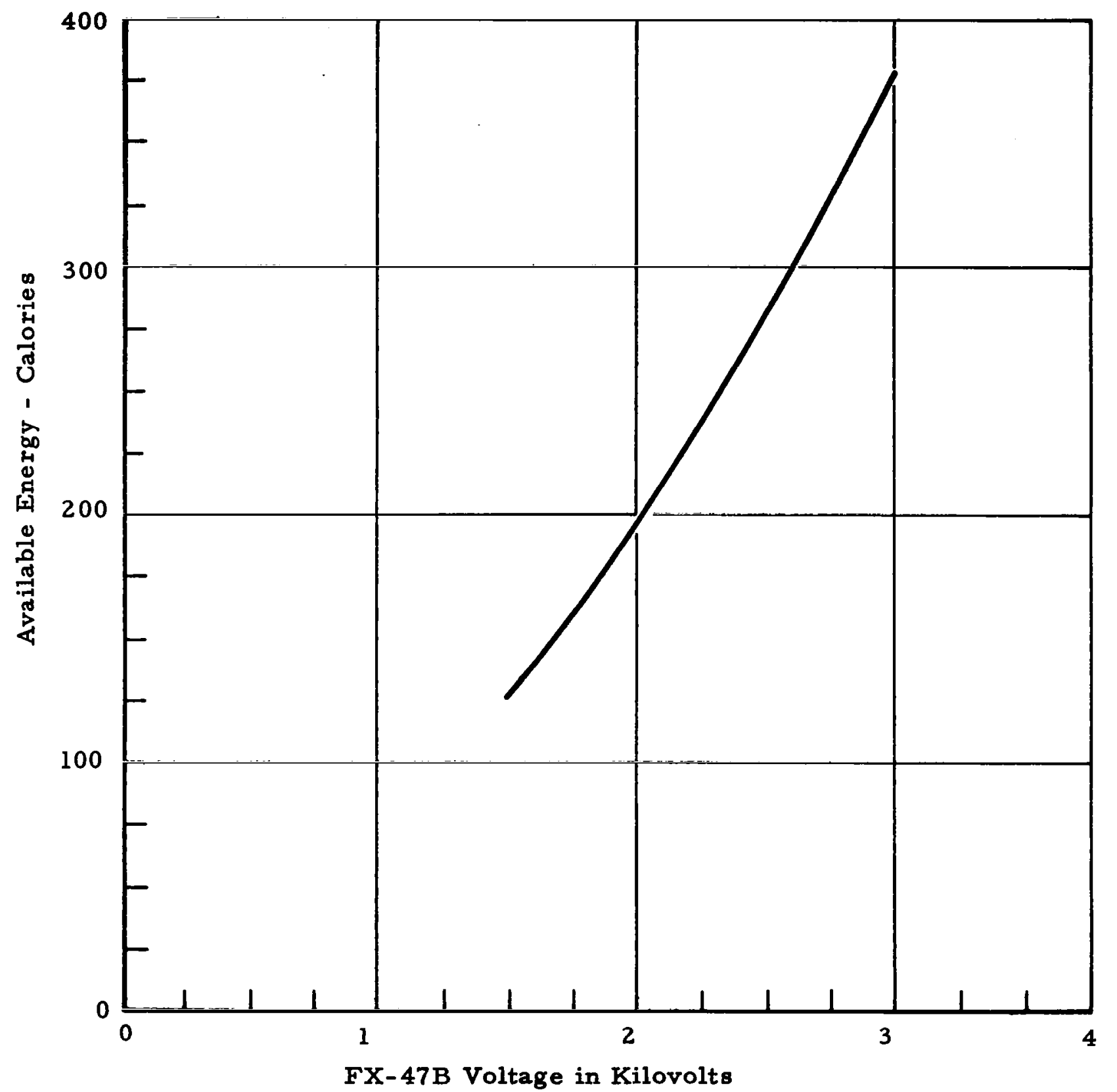

FIGURE 11 ENERGY AVAILABLE INSIDE CELL VS FLASHTUBE VOLTAGE 


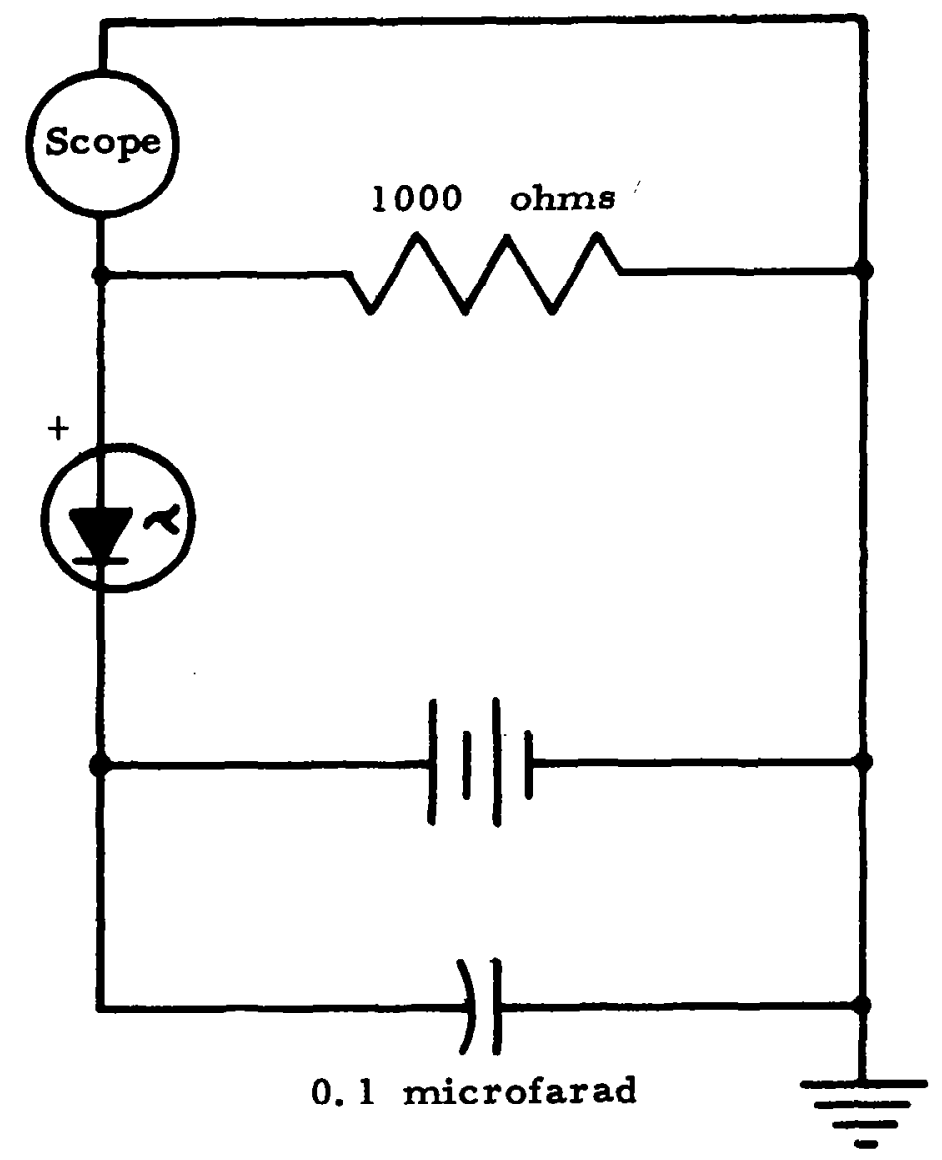

FIGURE 12 SILICON PHOTODIODE CIRCUIT 


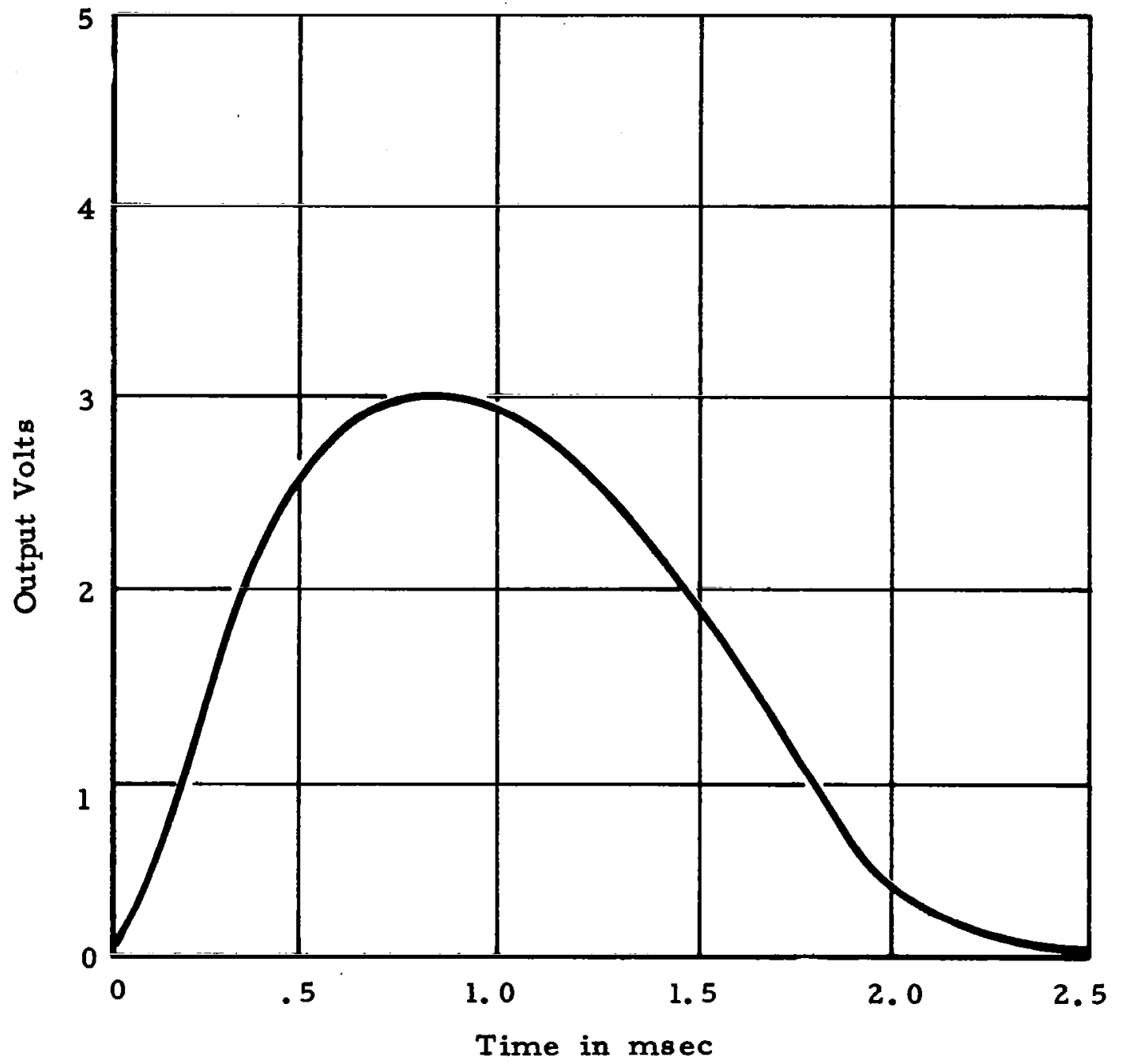

FIGURE 13 TYPICAL SD-100 LIGHT PULSE 
Because the wavelength response of the SD-100 was limited to the 0.3 to $1.2 \mu$ region, there was some concern that the observed pulse shape might be inaccurate. If, for example, at the midpoint of the flash the fraction of short wavelengths increased, the photodiode would underestimate the peak height.

However, Church et al (Reference 10) measured the spectral radiance of a xenon plasma at peak current densities of $1000 \mathrm{~A} / \mathrm{cm}^{2}$ and $4480 \mathrm{~A} / \mathrm{cm}^{2}$. They found in both cases that the radiance was nearly constant from about 4000 to $9000 \mathrm{~A}$, falling sharply toward shorter wavelengths and falling gradually toward longer wavelengths. For the FX-47B under the conditions of the $3 \mathrm{kv}$ flash, the average current density is about $3000 \mathrm{~A} / \mathrm{cm}^{2}$ and the peak is estimated to be in the vicinity of $4000 \mathrm{~A} / \mathrm{cm}^{2}$. It is then expected that Church's value would be applicable. According to his results, the peak of the xenon plasma radiance does not shift toward shorter wavelengths with higher temperatures, as the blackbody radiance peak does. The small fraction of the energy which has wavelengths shorter than $3000 \mathrm{~A}$ (a few percent) is nearly the same for the 1000 and $4480 \mathrm{~A} / \mathrm{cm}^{2}$ cases and therefore insensitive to current density. Some experimental checks were made to determine that Church's results were indeed applicable to the flashtube. First, light from the flash was focused on the entrance slit of a spectrophotometer. A photomultiplier at the exit was set at a series of wavelengths from 3000 to $11,000 \mathrm{~A}$ and its output pulse in each case was displayed on an oscilloscope and photographed. Each wavelength setting, of course, required another flash of the FX-47B, and measurements were repeated for several flash voltages. Calibration of the spectrophotometer was performed with a tungsten filament lamp with low output at short wavelengths. For this reason measurements at wavelengths shorter than $5000 \mathrm{~A}$ are not accurate, but a least in the 5000 to $9000 \mathrm{~A}$ region the flashtube output is found to be approximately flat in agreement with Church's results and a decrease is indicated at longer and shorter wavelengths.

In addition, measurements were made using a series of sharp cut-off filters in front of the SD-100 and comparing pulses photographed with and without the filters. The cut-off wavelengths covered the range from 3000 to $8000 \mathrm{~A}$ but the results were not actually interpretable bclow $4000 \mathrm{~A}$ bccause of the low response of the SD-100. However, in the 5000 to 9000A region the intensity again appeared to be nearly constant. Therefore, although these experimental results are not sufficiently accurate to provide a quantitative correction factor, they do produce confidence that Church's results can be employed, and that the SD-100 pulse is an accurate representation of the power output of the flashtube.

Dust Feed. - One of the major experimental problems was establishing a satisfactory method of introducing a uniform, reproducible cloud at several atmospheres in a small absorption cell without seriously coating the walls.

A series of attempted methods is listed here with their various advantages and disadvantages.

1. Wright Dust Feed Mechanism. - This commercially available unit was designed to feed dust into a gas at a steady, preselected rate while achieving deagglomeration through a high speed gas stream and impact plate. 
It was not operable at pressures much above atmospheric and was found to produce a cloud in bursts. Use of a surge tank to smooth the bursts was found unsatisfactory due to the rapid agglomeration of carbon particles in particular.

2. Bell Flow Valve. - This device, used in the dairy industry for homogenizing milk, is a compressed mass of fine wire producing a large number of narrow channels. The incoming gas jet was directed down on a mound of power which it then blew through a Bell flow valve mounted at the cell entrance. This gave a good dispersion with carbon powder.

With other powders clogging of the narrow channels prevented use of this device.

3. Powder Inside Cell. - A weighed powder sample was place in a small cup inside the entrance valve and was dispersed by the incoming gas stream. This method had the advantage of avoiding valve clogging and avoiding uncertainties in the amount of dust in the cell.

Unfortunately the agglomerates were not adequately broken up.

4: Vibrating Screen. - A completely different method involved placing the powder on a screen just above the cell and vibrating it electromagnetically to allow dust to sift down through the cell. This proved to be the only method to give a dispersion of tungsten powder, which appeared appreciably absorbing to the eye.

The clouds achieved with powders of less dense materials were not sufficiently absorbing to result in significant temperature rises. And even tungsten clouds which appeared somewhat opaque to the eye did not result in temperature rises labove about $1500^{\circ} \mathrm{C}$. Efforts to use tungsten powder were abandoned.

5. External Cup. - Finally the mechanism shown in Figure 14 was settled upon. In this a weighed amount of powder was placed in a cup outside the check valve. Gas admitted by opening the solenoid valve flowed through the powder at high velocity and carried it into the cell.

The relay which opened the solenoid valve activated a variable time delay circuit which at the end of its delay, triggered the flash tube. It was possible to adjust the timing to allow the cell to fill to the desired pressure (about $200 \mathrm{msec}$ ) but not allow extra time in which additional agglomeration and settling would occur.

With such a small (1/2 inch diameter) cell there was always some settling of powder on the walls. However, with this arrangement it was found from examination of the tube afterwards, to be fairly uniform over the entire cell. This was assumed to indicate a uniform cloud, too.

Having achieved a useable dispersion it was necessary to make some determinations of the amount of powder in the cell, the particle size.distribution and the absorption of the cloud. The absorption was experimentally the most significant. 


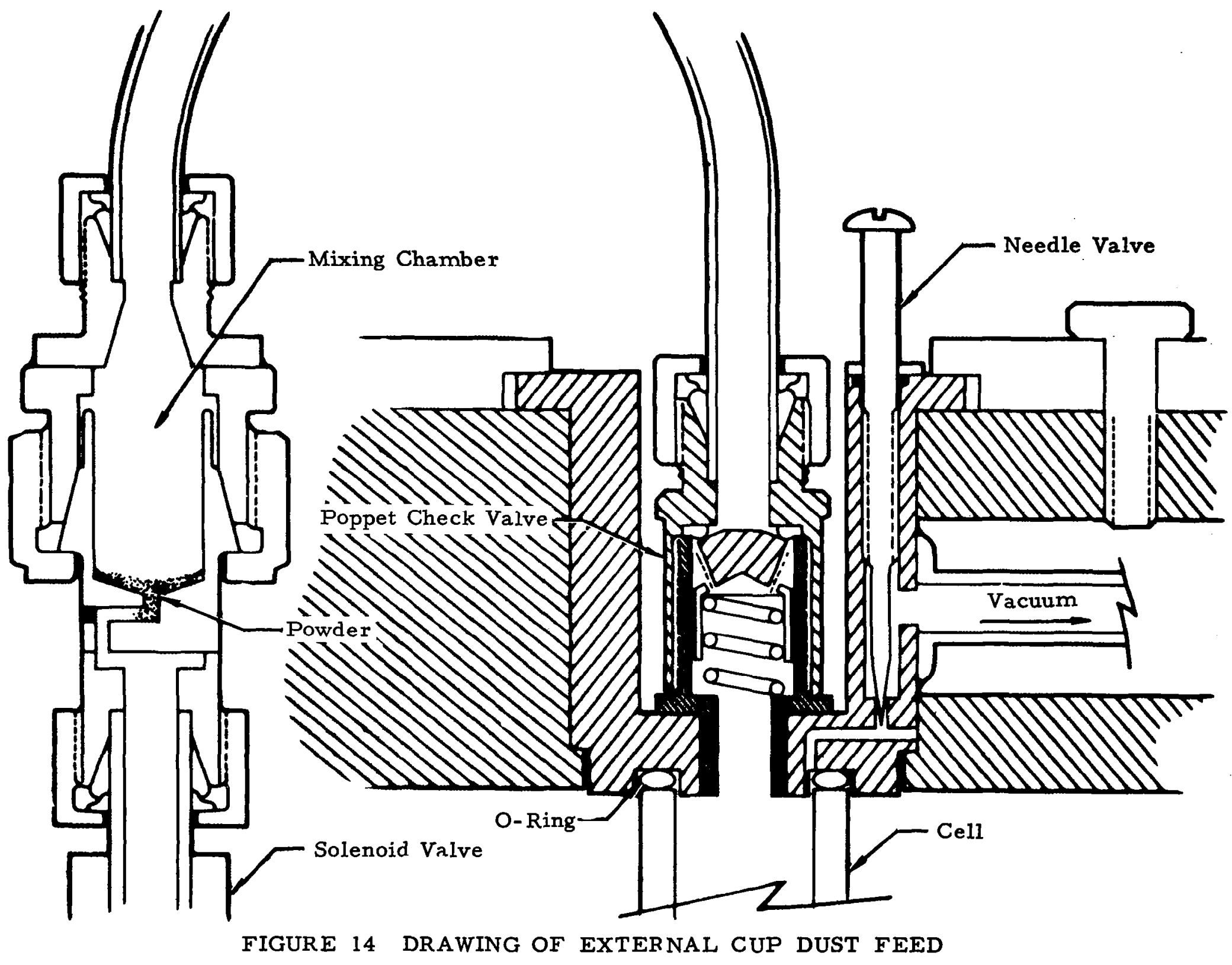


Cloud Absorption Measurements. - To determine the absorption of the cloud and to check on its uniformity, two pairs of small holes were cut in the reflector on opposite sides of the absorption cell. One pair was about 1/4 of the way from the top of the cell and the other about $1 / 4$ of the way from the bottom. A small dc lamp with lens was positioned outside one upper and one lower hole and an SD-100 photodiode was placed at each opposite hole to receive the transmitted beam. To avoid reflections, dull black paper with suitable holes cut in it was used to line the elliptical reflector. With this precaution the detectors were each sensitive only to changes in the corresponding light source and showed no interdependence. The photodiode output was terminated in a $1000 \Omega$ resistor in each case and the signals were fed to an oscilloscope. The photodiodes have a linear response over a wide range of intensity. Light transmission measurements were made before and during admission of the cloud.

The two pulses were displayed simultaneously on the oscilloscope screen and it was observed that the cloud reached the second position about $30 \mathrm{msec}$ after it reached the first. A typical pair of curves is shown in Figure 15. The loss of transmitted light was nearly the same at both positions and found to be repeatable within \pm 10 percent for the same conditions of powder weight and gas pressure.

$50+10$ percent of transmission was found to be obtained with the following weights of powder placed in the external cup and blown in with 5 atm of gas: $\mathrm{TaC} ; 50 \mathrm{mg}$; Fe, $50 \mathrm{mg}$; C, $3 \mathrm{mg}$. These are the materials and quantities used in most of the pressure rise measurements.

It is also possible that an appreciable fraction of the absorption was due to dust on the cell wall. Collection of dust on the walls during cloud injection has been noted throughout this work and many efforts have been made to minimize it. Eventually the entire suspension will either adhere to the wall or fall to the bottom of the cell, but this is observed to require a time long compared to the 2 msec flash.

At any time the transmitted intensity is $I-I_{o} e^{-K}$ with $K=n \sigma d+K_{w a l l}$ where $\mathbf{n}$ is the density of particles in suspension, $\sigma=$ absorption cross section, $\mathrm{d}=$ tube diameter and $\mathrm{K}_{\mathrm{wall}}$ takes into account the absorption of powder collected on both walls.

Suppose that all the particles were uniformly distributed throughout the volume at time $A$ and uniformly distributed on the wall (with none in sus-. pension) at a later time $B$. It is interesting to note that the measured absorption is less at timeB; i.e., the transmission is greater when the particles are on the wall. This is purely geometrical effect as seen below. At time $A, I_{A}=I_{0} e^{-(n d \sigma)}$ for particles uniformly distributed with density $n$ throughout the volume of a tube of diameter $d$, height $h$. The total number of particles is:

$$
N=\frac{\pi d^{2}}{4} \quad h n
$$




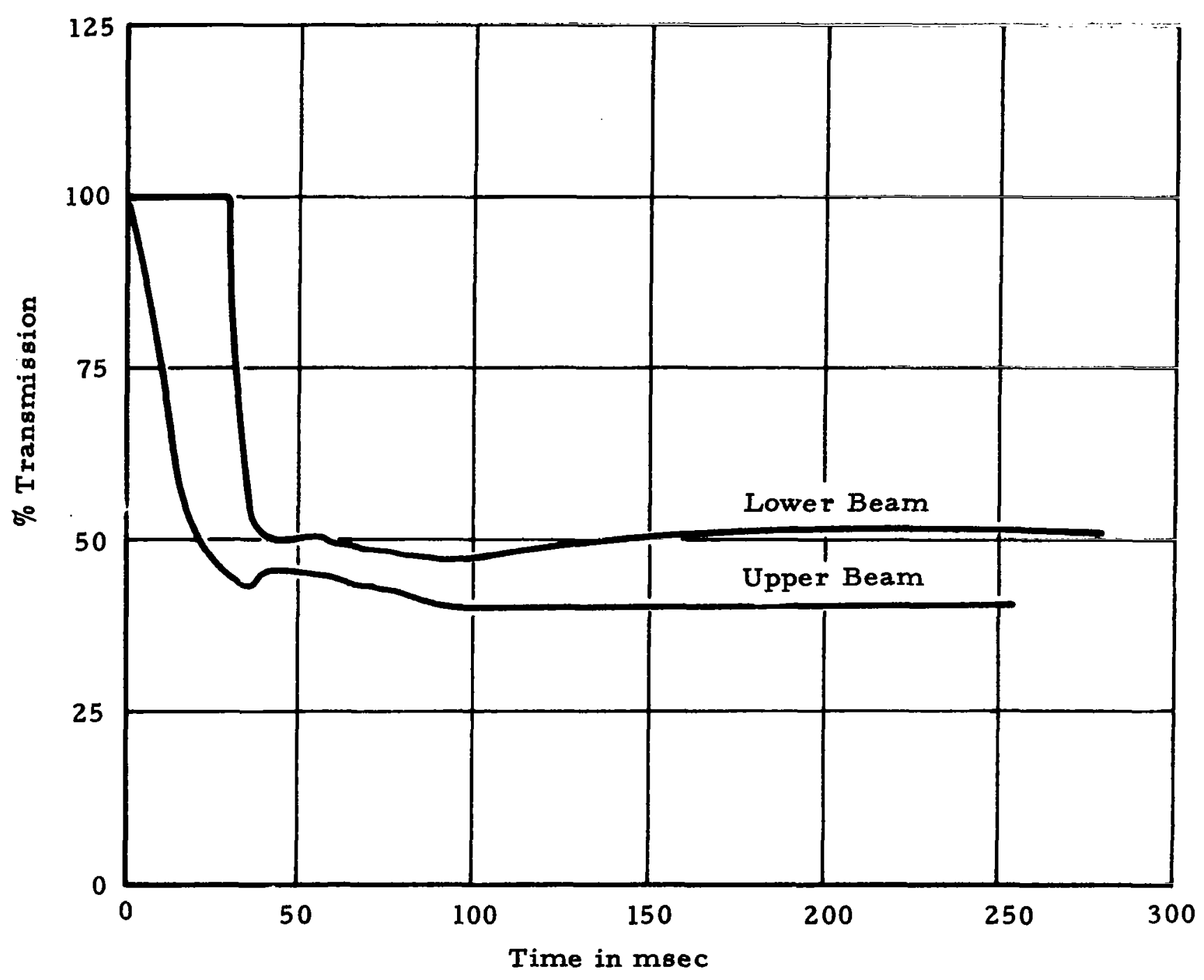

FIGURE 15 TRANSMISSION OF COLD CLOUD 
and if these collect uniformly on the cylinder wall there are

$$
\frac{\pi d^{2} h n}{4 \pi d h}=\frac{n d}{4}
$$

per unit surface area. Since the beam traverses the wall twice it will encounter $\frac{1}{2}$ nd particles per $\mathrm{cm}^{2}$. Thus,

$$
I_{B}=I_{0} e^{-\frac{n d \sigma}{2}}>I_{A}=I_{0} e^{-n d \sigma}
$$

so that particles in suspension are twice as effective in producing absorption as particles on the wall.

Transmission measurements made after several minutes are generally in agreement with this prediction of a 50 percent decrease in absorption with settling of particles on the absorption cell wall.

A brownish coating, frequently noted on the quartz wall after a high temperature flash, was found to be due to silicon. This indicated that particles heated while in contact with the wall, or striking the wall while hot, had reduced the $\mathrm{SiO}_{2}$, leaving $\mathrm{Si}$. The silicon coating was particularly noticeable in regions where powder had settled on the wall before the flash, indicating that the effect was largely due to particles heated while in contact with the quartz surface.

On the other hand there was some evidence that particles initially on the wall were driven off during heating presumable by a gas layer at the quartz surface. If, for example, a cloud was introduced and then allowed a long wait, say 30 minutes, before flashing, all the dust had settled on the wall. Because of the large mass of the quartz tube only about a $20^{\circ} \mathrm{C}$ temperature rise was expected if all the flashtube energy were deposited in the wall. But the pressure rise detected in such a case corresponded to a temperature increase of, perhaps, $1000^{\circ} \mathrm{C}$ indicating that part of the dust had been driven into suspension.

Reduction of tranmission is, of course, due to reflection and scattering as well as actual absorption. During the course of the maximum temperature experimentation it became evident that information about changes in transmission during the flash was desirable. This was tried in three ways. One was to set up an FX-33 flashtube with a 50 joule, $100 \mu \mathrm{sec}$ pulse and to flash it before, and at various times during the main flash. The FX- 33 was mounted outside a $1 / 4$ inch hole in the reflector so that its light passed through the absorption cell and through a $1 / 4$ inch hole in the opposite side of the reflector. To separate the FX-33 flash from the intense background light of the FX-47B, additional collimation was necessary. A $5 \mathrm{ft}$ long tube with $1 / 8$ inch holes at each end (and the optical detector mounted at the far end) was aligned with the holes in the reflector. With this arrangement the short pulse was clearly visible above background as shown in Figure 16. The optical detector in this case was a computer readout cell which has a greater sensitivity than the SD-100. 


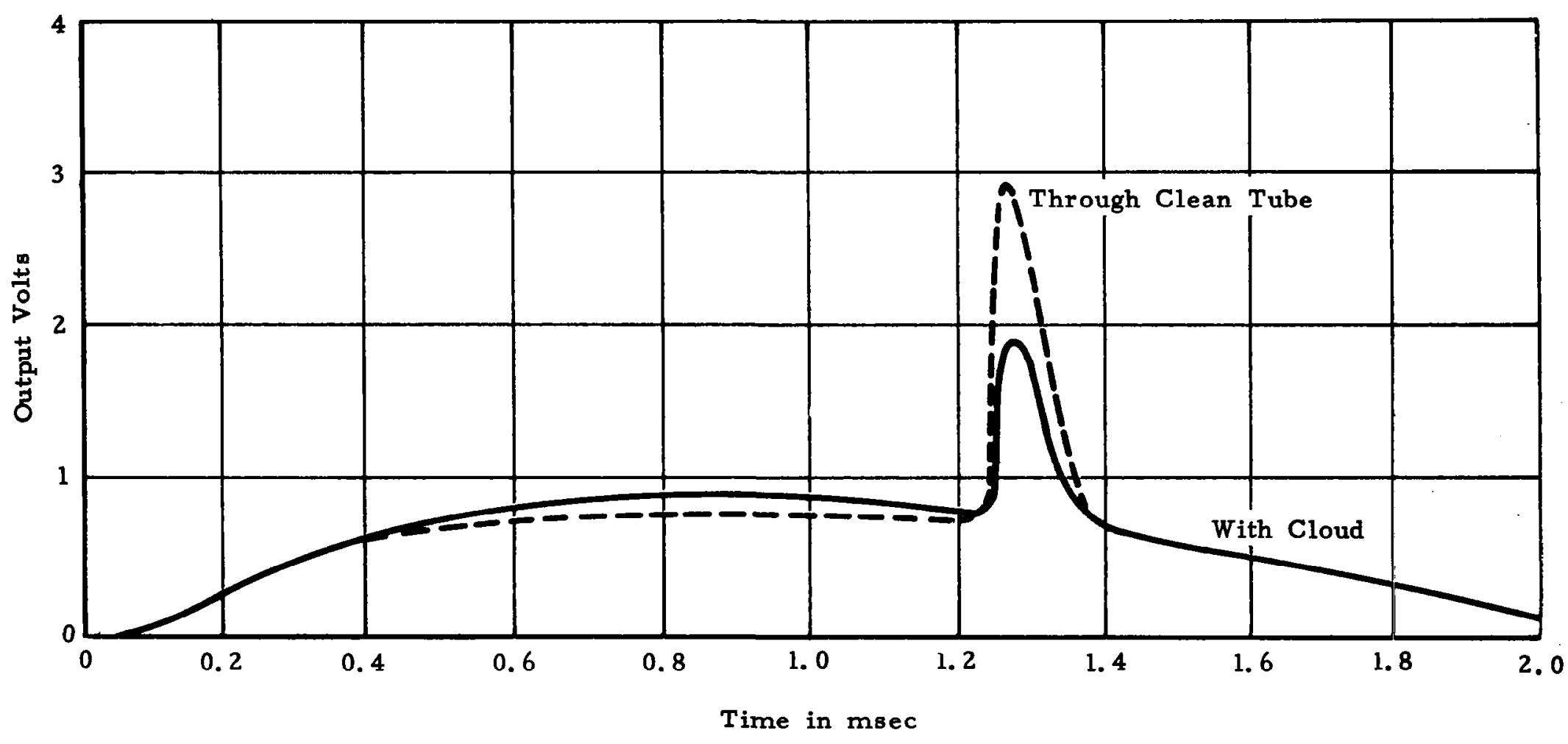

FIGURE 16 FX-33 FLASH SEEN THROUGH CELL DURING FX-47 FLASH 
As it was not possible to recharge the capacitor rapidly enough to have more than one FX-33 flash during the 2 msec main flash, the different times were obtained on successive FX-47B flashes. This raised the possiblity of different cloud densities on successive flashes, but the loss of transmission of the short flashes was found to be $50 \pm 10$ percent regardless of the time during the main flash. This is consistent with variations in the cold cloud measurements and does not indicate transmission changes during the flash.

To obtain a coninuous monitoring of the cloud transmission during a flash the second type of measurement used a plane mirror mounted in such a way that some of the light from the mian flash was reflected through the cell and into the collimator.

The transmitted light was measured with and without a cloud in the absorption cell. Ratios of the signal transmitted through the cloud to that through the clean cell varied randomly during the $2 \mathrm{msec}$ period but fell within the $50 \pm 10$ percent range. These variations are attributed to swirling in the cloūd.

To further reduce background light from the flashtube the third method employed a 6300A cw laser beam directed through the absorption cell and into a spectrometer set on the laser wavelength. This again allowed a continuous measurement during the flash. To overcome the dispersing effect of the quartz tubing, lenses were mounted before and after the cell so that light rays passed nearly perpendicularly through the walls. Striations in the quartz produced interference patterns in the laser light as it impinged on the spectrograph slit so that very small relative motions of the beam and cell gave large changes in light intensity. By observing laser transmission through an evacuated cell during a flash it was possible to detect changes due entirely to motion. If such changes were very small a cloud was introduced and the measurement repeated. In most cases the changes due to motion were found to be large but these were minimized by shock mounting the individual parts well away from the choke and high current leads. Finally a diverging lens was used to spread the light impinging on the spectrometer entrance slit in such a way that a light band was centered on the slit. A few measurements free of motion effects were obtained by this technique and these again indicated a constant transmission during the main flash.

In no case was there any transmission variation which could be attributed to collection of dust on the walls, to ejection of collected particles from the walls or to decreased transmission of the wall due to reduction of the quartz and formation of the silicon coating.

Quantity of Dust. - The amount of powder placed in the external cup was known to +0.1 $\mathrm{mg}$ but the weight of that which entered the cell could not be conveniently determined. Two types of estimates were made of this quantity from the residue in the cup.

In some cases, after the cloud was blown into the cell, the residue in the cup was shaken out and weighted. 
In other cases, after the original could was blown into the cell, a clean cell was inserted and a new cloud was made by blowing the residual powder. Visual observations were made of original and second clouds. On the basis of these observations it is estimated that the 50 percent cold absorption cases correspond to suspensions of: $\mathrm{TaC} ; 20 \mathrm{mg} ; \mathrm{Fe} ; \mathrm{C} ; 2.5 \mathrm{mg}$. For the typical absorption cell volume of $22 \mathrm{~cm}^{3}$ and $1.3 \mathrm{~cm}$ inner diameter these weights give the following extinction cross sections for 50 percent transmission.

$\begin{array}{lc}\text { Seed } & \sigma \mathrm{cm}^{2} / \mathrm{gm} \\ \mathrm{C} & 4700 \\ \mathrm{Fe} & 470 \\ \mathrm{Tac} & 580\end{array}$

Particle Size Distribution. - To estimate the size distribution of the particles in the cloud and to roughly determine the amount of agglomeration, millipore filters were introduced and allowed to capture the particles. A circular filter supported between small 0 -rings was placed inside the quartz tube near the end opposite the entering cloud. However, a cloud of the density necessary for absorption coated the filter so heavily it was not possible to examine individual particles. Using a much thinner cloud than that required for absorption, samples were caught on millipore filters and examined. There are two difficulties with this procedure. A denser cloud may experience more agglomeration than was indicated so that this method under estimates the average particle size. On the other hand, some agglomerates may have occurred on the filter, not in suspension, so that this method over estimates the average size. It is not known how much one of these effects compensates for the other, so the results can only be regarded as an indication of the particle size distribution.

From electron and optical microscopic examinations (Figures 17, 18 and 19) the particle radii range between 0.1 to $10 \mu$ for $\mathrm{TaC}, 1$ to $5 \mu$ for $\mathrm{Fe}$, and 1 to $20 \mu$ for $C$. These approximate values produce the following ratios of extinction to geometrical cross sections:

\begin{tabular}{ll} 
Seed & \multicolumn{1}{c}{$\sigma / \mathrm{A}$} \\
& 0.01 to 1 \\
$\mathrm{Fe}$ & 0.1 to 0.5 \\
$\mathrm{C}$ & 0.02 to 1
\end{tabular}


As the filter material becomes transparent when wet with oil, transmission measurements were made using an oil immersion microscope (magnification 1600X). And in the case of TaC electron micrographs were made with a 6300X magnification. Typical photomicrographs are shown in Figures 17, 18, and 19, for $\mathrm{TaC}, \mathrm{Fe}$ and $\mathrm{C}$ respectively. Also shown in these figures are photomicrographs of particles of the same material caught on a piece of glass at the bottom of the cell and which were exposed to a flash.

There is clearly a wide range of particle sizes in each case from less than $0.5 \mu$ to about $5 \mu$ with little apparent difference before and after a flash except that the carbon shows more agglomeration afterwards.

Pressure Transducer. - In the constant volume absorption cell the pressure rise is proportional to the temperature rise until such effects as seed vaporization and gas dissociation become important. And as there is no reliable way of measuring the gas temperature directly, the pressure measurement is the most satisfactory method.

The Kistler quartz crystal pressure transducer used had a response time of about $10 \mu \mathrm{sec}$ and was suitable for pressure to 15,000 psi. The output (a charge buildup) was fed into a Kistler charge amplifier which converted this to a voltage signal of a few volts which could be displayed on the oscilloscope.

As described earlier the transducer was mounted in the triangular frame just at the bottom of absorption cell. It was found necessary to cover it with a shield which prevented incident light but permitted gas entry through a series of holes in the sides. Absorption of radiant energy from the flash caused thermal distortion of the diaphram over the quartz crystal and gave a negative pressure signal. As will be seen in the Results Section, the gas heating as measured by the pressure rise decreased while energy input to the cell was still rising. It was feared that this might be due to errors in the pressure measurements.

To establish that the transducer readings were actually reflecting the pressures in the absorption cell and that these pressures were those of the heated gas, several checks were made on the validity of the data.

An effort was made to detect any possible leaks in the system, either around the 0 -rings at the ends of the absorption cell or, less likely, through the check valve. First with helium in the system a helium leak detector was set up with "sniffer" inside the elliptic reflector cavity. No leak during a flash was detected. It was established that this arrangement was very sensitive to a small leak so that lack of detection was significant.

The pressure transducer was then mounted behind the check valve. No change in pressure could be detected during a flash, indicating no significant leak through the valve. And finally a leak was introduced intentionally through the needle valve. This was found to have no large effect on the pressure pulse, but actually resulted in a slightly higher pressure rise, perhaps by increasing the cloud density. 
Before Flash

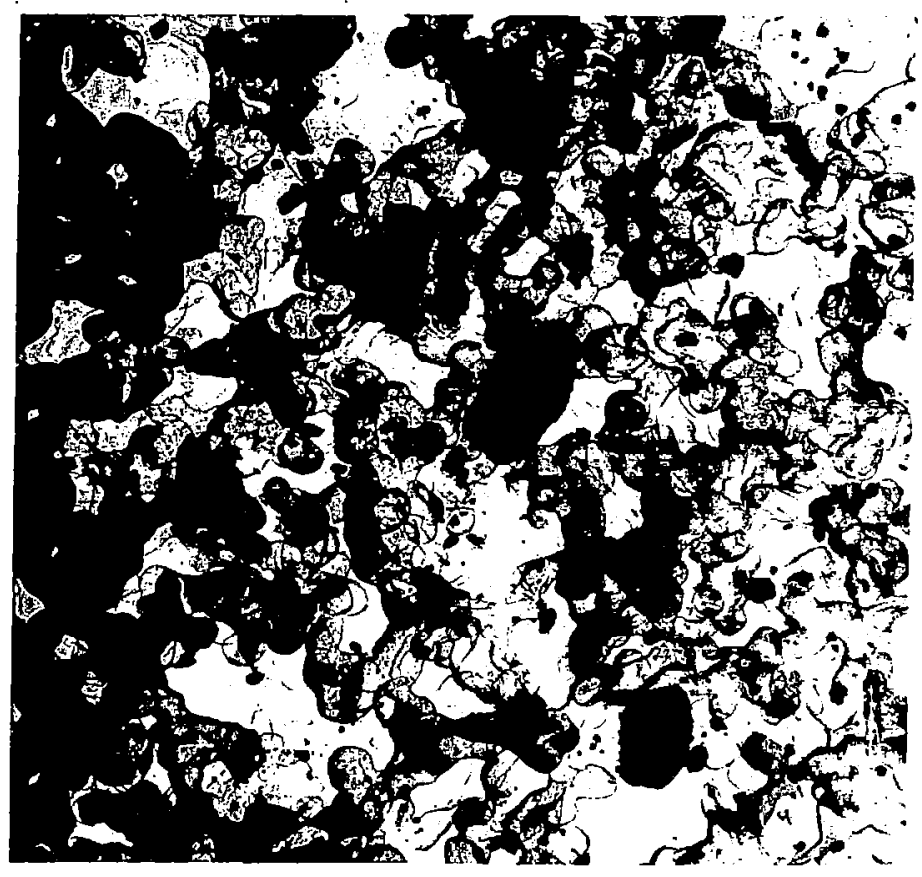

Electron Microscope Photomicrograph

After Flash

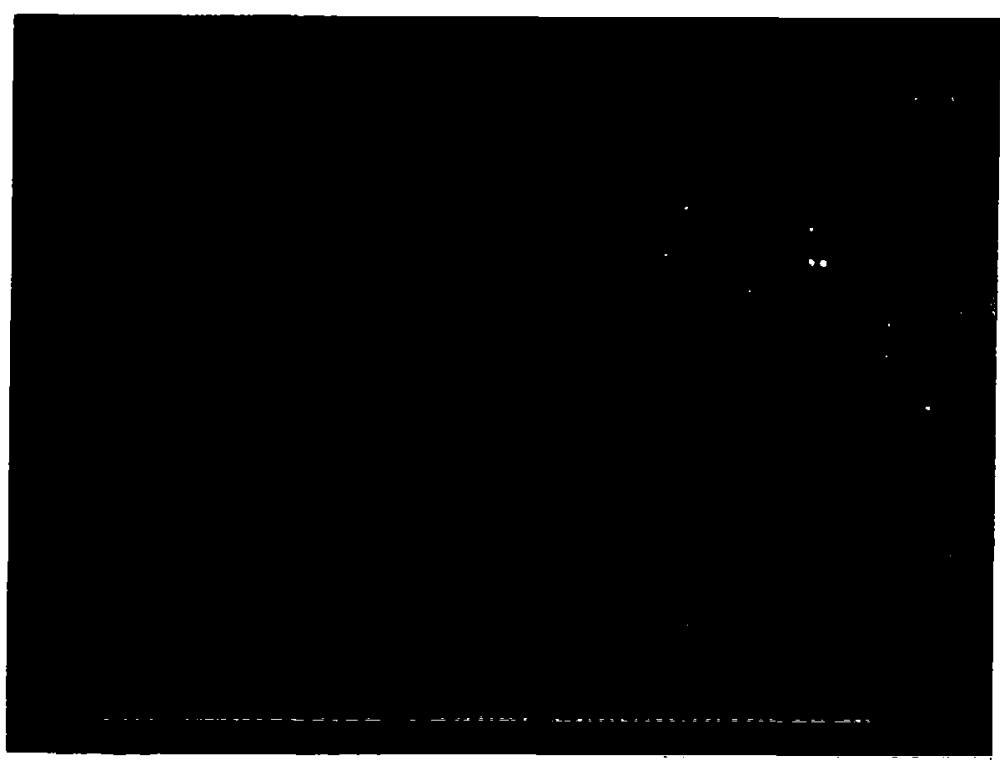

Oil Immersion Optical Photomicrograph (Na Light)

FIGURE 17 PARTICLE SIZE DISTRIBUTION (TaC) 


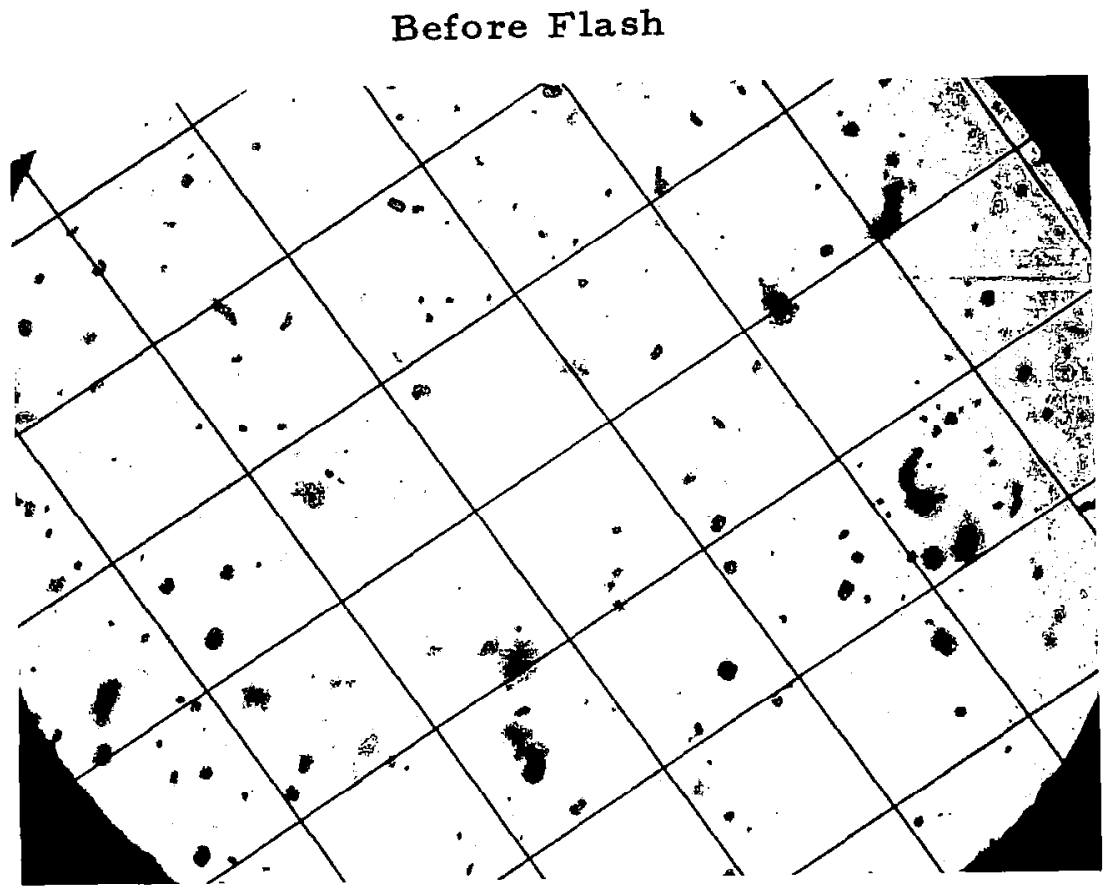

Oil Immersion Optical Photomicrograph

After Flash

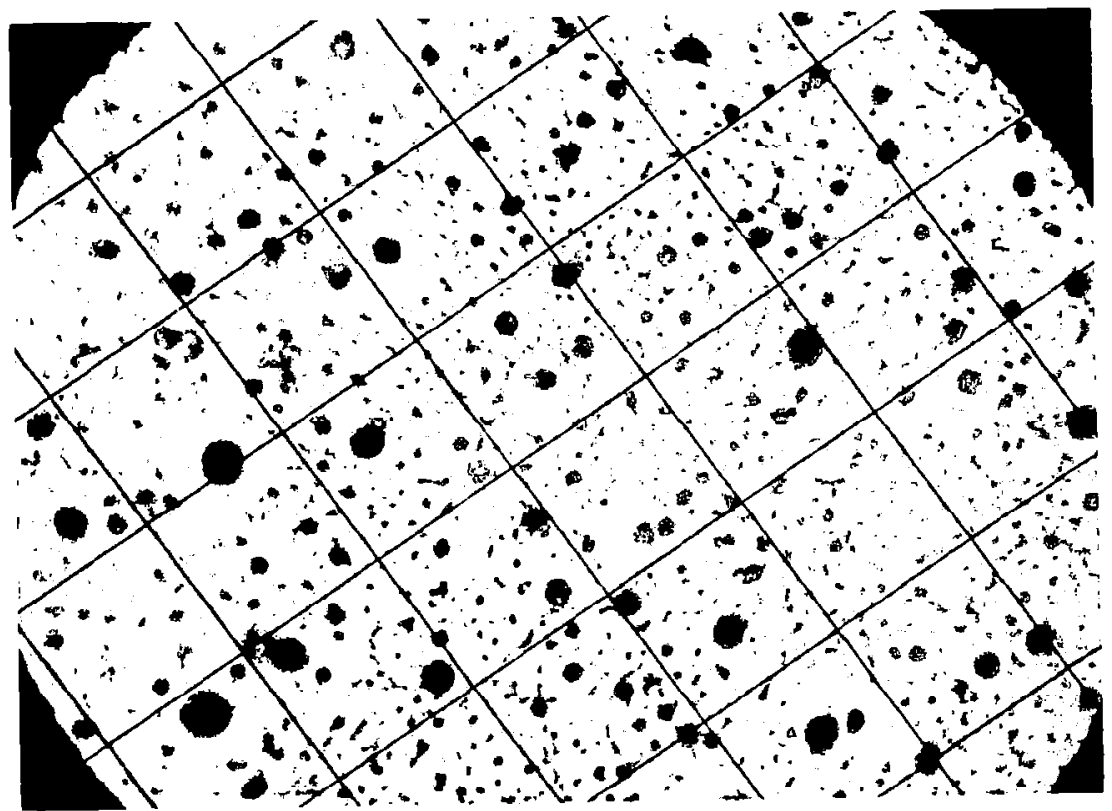

Oil Immersion Optical Photomicrograph

FIGURE 18 PARTICLE SIZE DISTRIBUTION (IRON) 


\section{Before Flash}

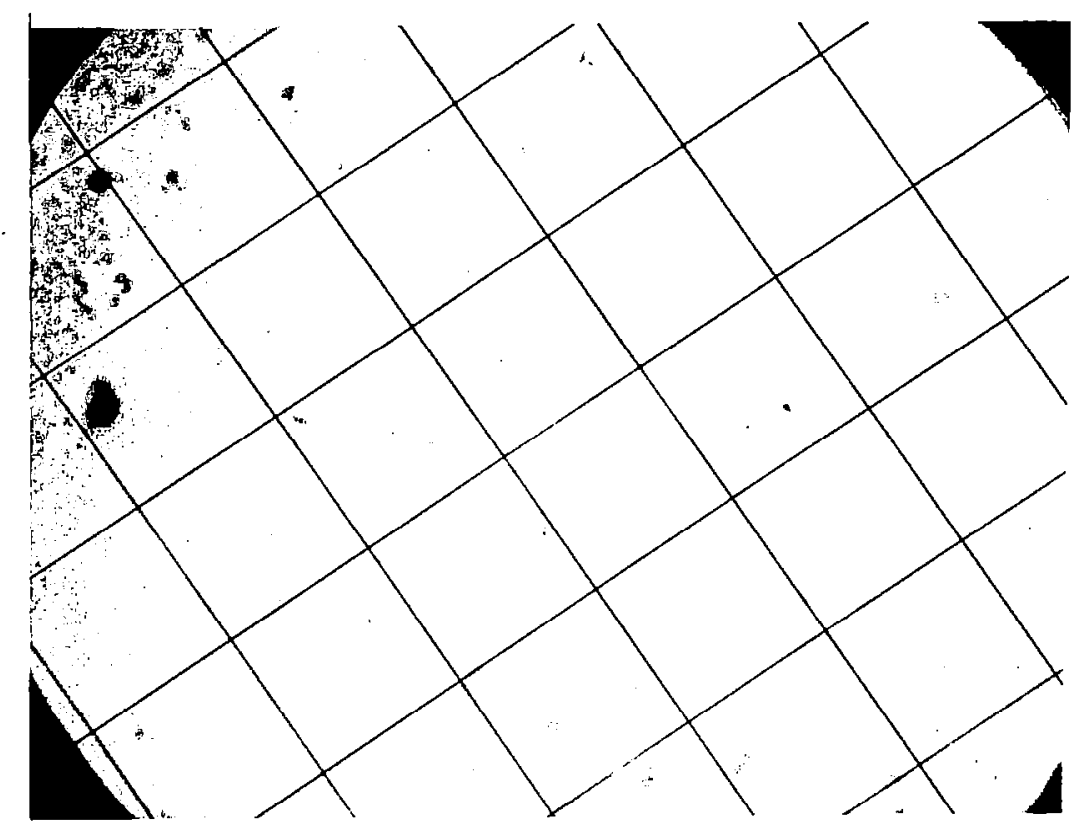

Oil Immersion Optical Photomicrograph

After Flash



Oil Immersion Optical Photomicrograph FIGURE 19 PARTICLE SIZE DISTRIBUTION (CARBON) 
When the pressure transducer was mounted in its normal position at the end of the cell and the pressure was followed on a long time scale it was found that after the flash a negative pressure signal occurred with about a 10 second time constant. It was finally estalished that this was due to conducted heat distorting the diaphram over the quartz crystal and giving a negative pressure signal. This was the same effect which had been observe when radiant energy from the flash heated diaphram and which was eliminated by use of a light shield. The time for conductive heating was too long for the negative signal to have any effect on the pressure pulse during the few milliseconds of interest, so it could not produce discrepancies in the results.

Maximum Temperature Measurements. - The major portion of the experimental work consisted of observing pressure pulses for various seeds in both helium and hydrogen and seeking the conditions which gave the maximum temperature rise. The pressure pulse and the light pulse were displayed simultaneously on the oscilloscope and, as each case gave a single pulse, the screen was photographed. The data therefore are in the form of oscilloscope photographs. Measurements were made as a function of the flashtube voltage and gas pressure for several seed materials, primarily C, Fe and $\mathrm{TaC}$, and the two gases. A typical photograph is shown in Figure 20 which represents $\mathrm{TaC}$ in 5 atm $\mathrm{He}$ for a $2 \mathrm{kv}$ flash. The time scale is $0.5 \mathrm{msec} / \mathrm{cm}$ and the light pulse is seen to be about $2 \mathrm{msec}$ in length. The pressure peak occurred at about $1.5 \mathrm{msec}$ and corresponded to a peak temperature of about $2700^{\circ} \mathrm{K}$.

Emission. - To gain some information about the seed temperature as distinct from the gas temperature an effort was made to look at the emission from the absorption cell. The problem here, of course, is the intense background light from the flash. To reduce this background a $1 / 4$ inch $o . d$. tube was extended through a hole in the reflector right up to the cell wall. A silicon photodiode was mounted at its other end outside the reflector. A $1 / 2$ inch diameter tube extended through the reflector and up to the tube on the opposite side, giving a dark background. With no gas in the cell a signal was still obtainea during a flash from light refracted by the cell walls, but in most cases the light emitted by the hot gas exceeded this background. Measurements were made comparing the photodiode pulses without and with various gas-seed combinations in the cell. Figure 21 shows this emitted light from $\mathrm{TaC}$ in He during a $3 \mathrm{kv}$ flash and Figure 22 shows the same thing for Fe. For TaC, an interesting double peak in the intensity is observed. This has been variously attributed to emissivity changes associated with phase changes in the seed material; to change in cloud absorptivity by ejection of cooler particles from the wall; and to cloud swirling in the gas. For Fe an intial peak occurs at $0.6 \mathrm{msec}$ but thereafter the light output from the seed follows the heating pulse. Since the tubes which make the observation possible also block part of the incident light from the observed region, local temperature and pressure differences may cause gas motion. The cause of these peaks has not been established but they are found to occur only in cases of high temperature rise. For gas temperature rises less than, say, $4000^{\circ} \mathrm{C}$ the emission from the cell follows the curve of the source. 



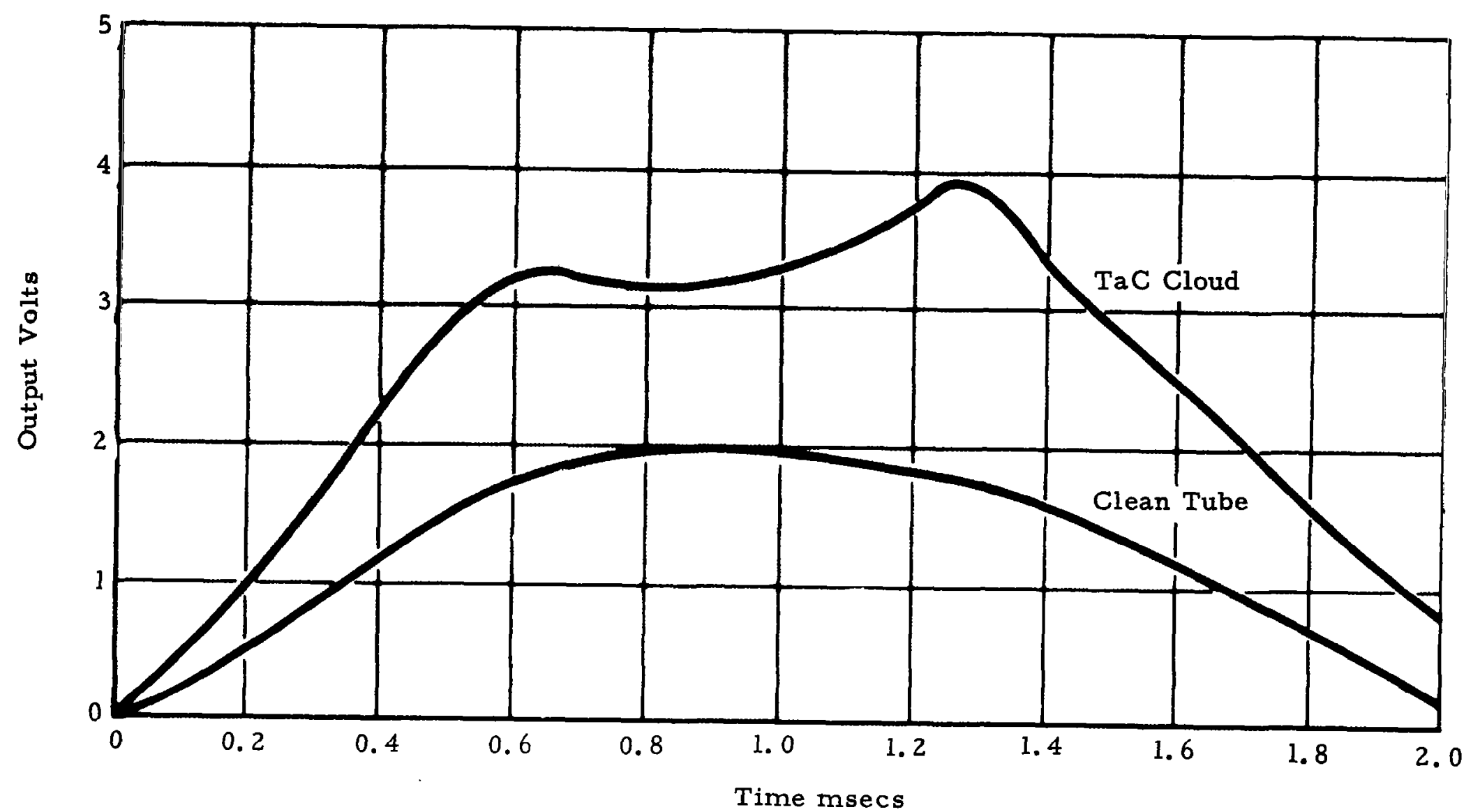

FIGURE 21 GLOW FROM TaC SEED 




FIGURE 22 GLOW FROM Fe SEED 


\section{RESULTS}

Results are given for the three seed materials, carbon iron and tantalum carbide for both hydrogen and helium gases. Some measurements were also made with tantalum, tungsten and tunsten carbide powders but since they did not lead to as high gas temperature rises as did iron and tantalum carbide, the number of measurements was very limited and they are not included. Carbon is of particular interest because of its low density and high emissivity and has been treated extensively even though it did not lead to high temperature rises.

The results of the maximum temperature measurements are presented in two ways: peak temperatures plotted vs available energy and energy content of the seeded gas plotted vs time. In all cases the temperature rise is calculated from the pressure rise assuming no change in atom number density. The range of validity of this treatment is indicated in the table below where the number of atoms for nominal quantities of particle material and gas are shown:

\begin{tabular}{llll} 
& \multicolumn{1}{c}{ Quantity } & \multicolumn{2}{c}{ Number of Atoms } \\
$\mathrm{TaC}$ & $20 \mathrm{mg}$ & $1.25 \times 10^{20}$ & $(\mathrm{Ta}, \mathrm{C})$ \\
$\mathrm{Fe}$ & $25 \mathrm{mg}$ & $2.7 \times 10^{20}$ & \\
$\mathrm{C}$ & $2.5 \mathrm{mg}$ & $1.26 \times 10^{20}$ & \\
gas & $2 \mathrm{~atm}, 22.5 \mathrm{~cm}^{3}$ & $12.1 \times 10^{20}$ & (no dissociation) \\
gas & $5 \mathrm{~atm}, 22.5 \mathrm{~cm}^{3}$ & $30.3 \times 10^{20} \quad$ (no dissociation)
\end{tabular}

Thus complete evaporation of particles produces a relatively small correction to the inferred temperature rise.

Measurements were made for flashtube voltages of $1.5,2.0$, and $3.0 \mathrm{kv}$. In each case a measurement of the available energy inside the quartz tube was made with a graphite rod and thermocouple. Peak temperatures are then plotted for energies corresponding to thcse four voltages. Most of the measurements were made with an intial pressure 5 atmospheres of gas, but a few were also made with 2 atmospheres at $3.0 \mathrm{kv}$. 
In figure 23 the points are shown for $\mathrm{TaC}$ in helium. At 5 atmospheres the temperatures achieved are seen to increase linearly with available energy. Decreasing the pressure to 2 atmospheres results in a further temperature rise. In this one case an additional flash was made at $3.5 \mathrm{kv}$ resulting in a gas temperature of about $6000^{\circ} \mathrm{K}$. The slope of the two points at 2 atm appears to be the same as the slope at 5 atm indicating that the seed material continues to absorb at high temperatures. However, this linear behavior does not extrapolate back to the original condition of $300^{\circ} \mathrm{K}$ with zero radiant energy. This result along with the relatively modest increase in temperature at $2 \mathrm{~atm}$ is not fully understood.

In Figure 24 the same results are presented for the hydrogen case. The hydrogen temperatures are lower than the helium temperatures because of the larger specific heat of hydrogen. Again temperature rise is seen to be proportional to available energy.

Figures 25 and 26 show the helium and hydrogen results for an Fe seed. In helium the 5 atm curve is linear to $2.5 \mathrm{kv}$ but shows a decreased slope beyond that. This is assumed to indicate a change in absorptivity at high temperatures, most likely due to $\mathrm{Fe}$ vaporization. However, when the pressure was reduced to $2 \mathrm{~atm}$ it was possible to reach a higher temperature. In hydrogen the temperatures achieved are lower and the points fall approximately in a straight line.

Figures 27 and 28 show the same results for a carbon seed. In helium the results show a gradual break from linearity with a slope generally lower than that for other seed materials. The hydrogen results show a plateau between 2.0 and $2.5 \mathrm{kv}$ followed by a further rise in temperature at $3.0 \mathrm{kv}$. This unusual result has been shown to be accurately repeatable, but its cause is not clear.

These results show substantial differences for the seed materials and gases tested. The salient features of this data can be summarized in the following points:

1. The tantalum carbide data for both gases shows a linear behavior which does not extrapolate to the absorption cell original conditions while iron and carbon generally satisfy this condition.

2. Linearity is observed in the peak temperature vs energy observation for $\mathrm{TaC}-\mathrm{He}, \mathrm{TaC}-\mathrm{H}_{2}$, and $\mathrm{Fe}-\mathrm{H}_{2}$ while departure from linearity is observe for $\mathrm{Fe}-\mathrm{He}, \mathrm{C}-\mathrm{He}$, and $\mathrm{C}-\mathrm{H}_{2}$.

3. An unusual plateau is observed for the $\mathrm{C}-\mathrm{H}_{2}$ measurements.

4. The inferred temperature rise is observed to continue to increase with increasing energy with the exception noted above. 


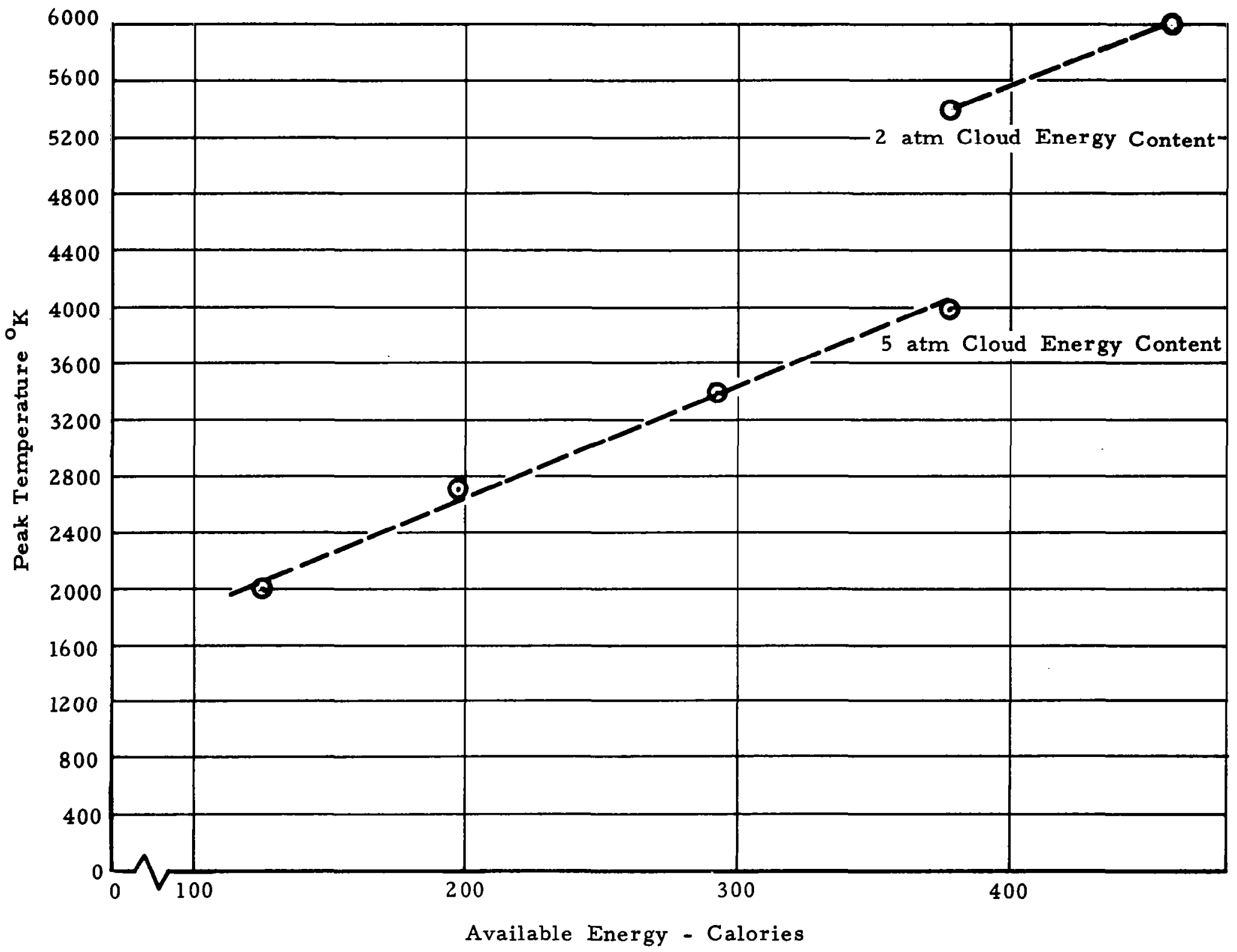


孛

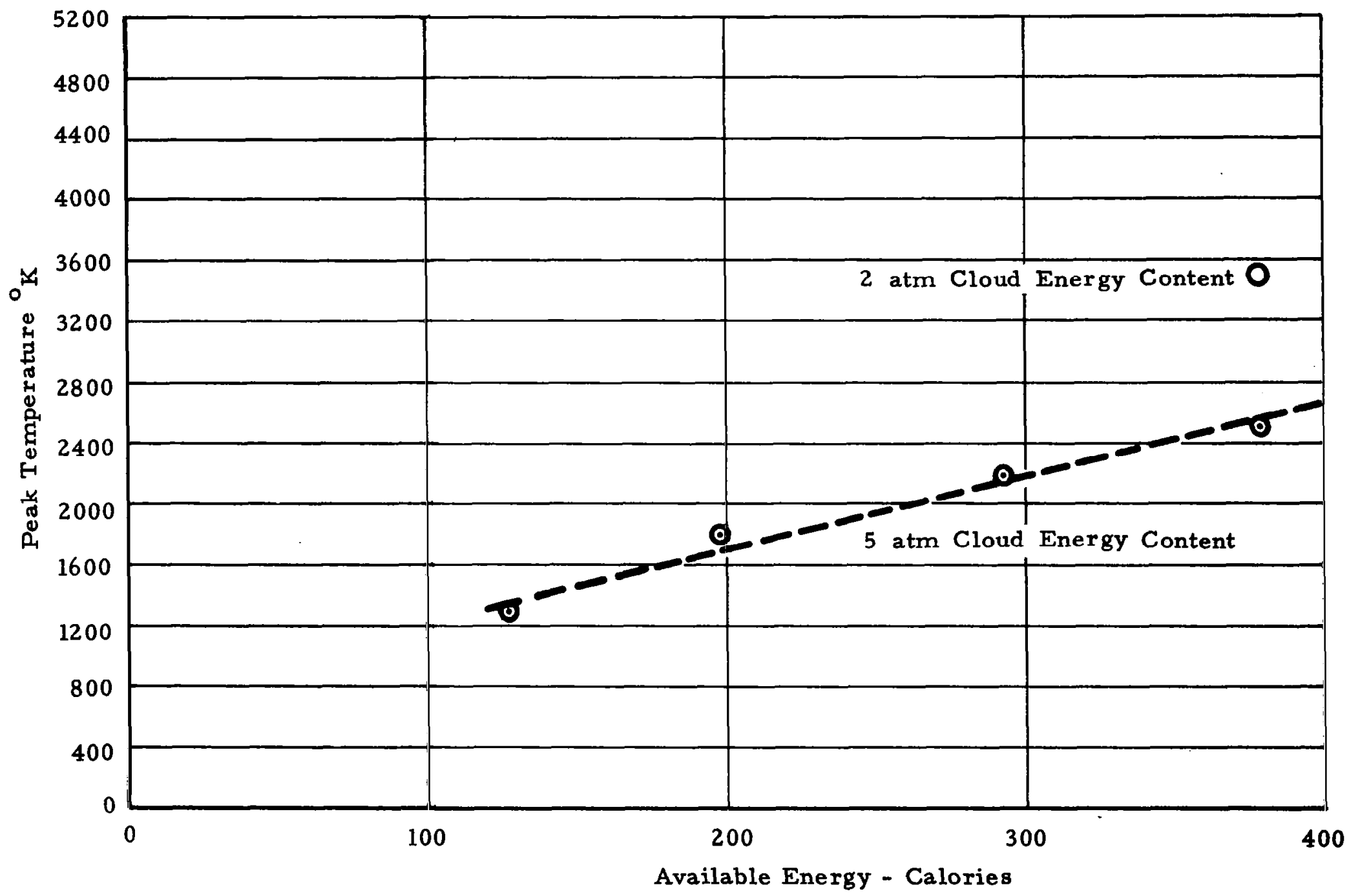

FIGURE $24 \quad 50 \mathrm{mg}$ TaC IN HYDROGEN 




FIGURE $25 \quad 50 \mathrm{mg}$ Fe IN HELIUM 
के

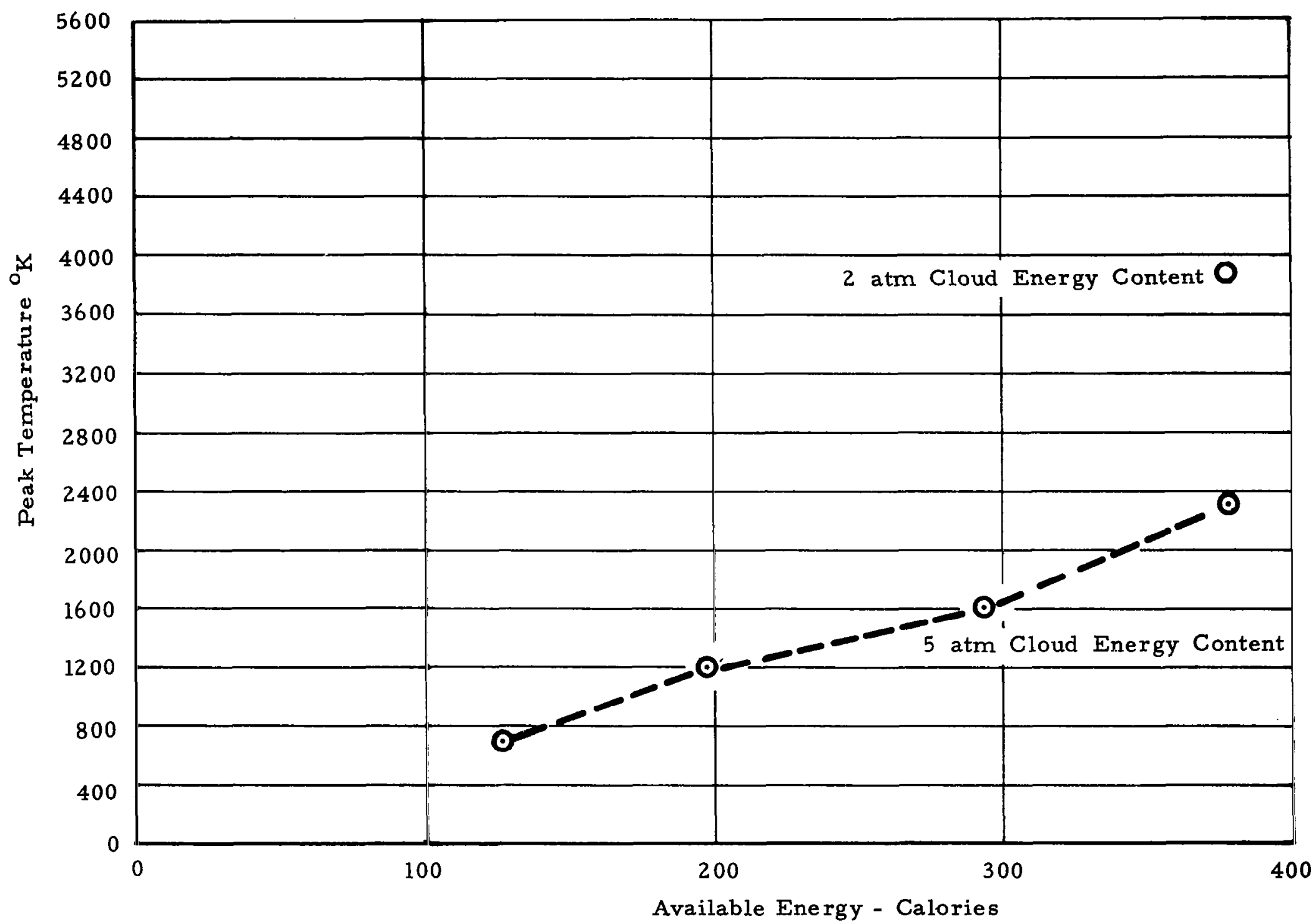

FIGURE $26 \quad 50 \mathrm{mg}$ Fe IN HYDROGEN 


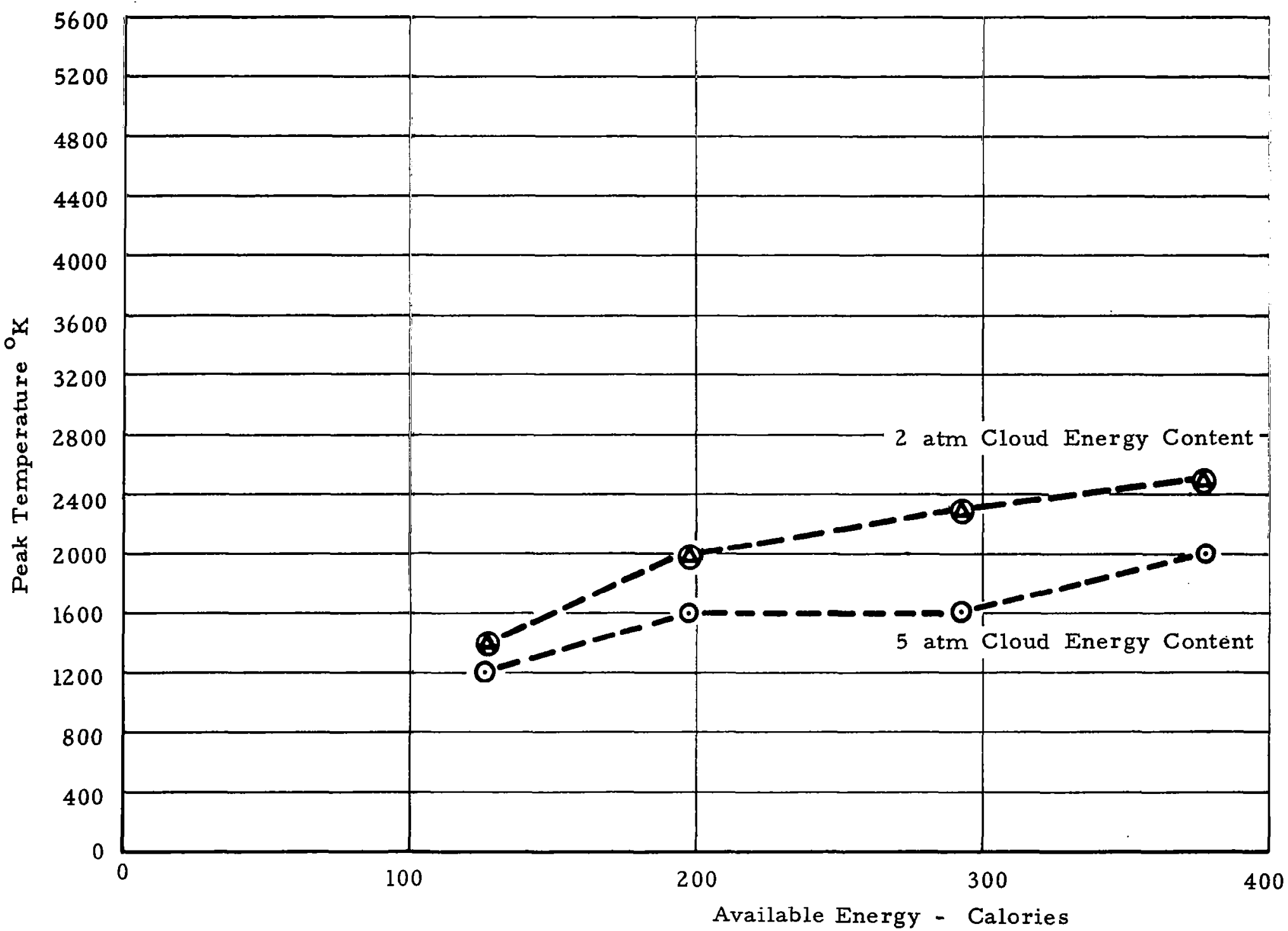




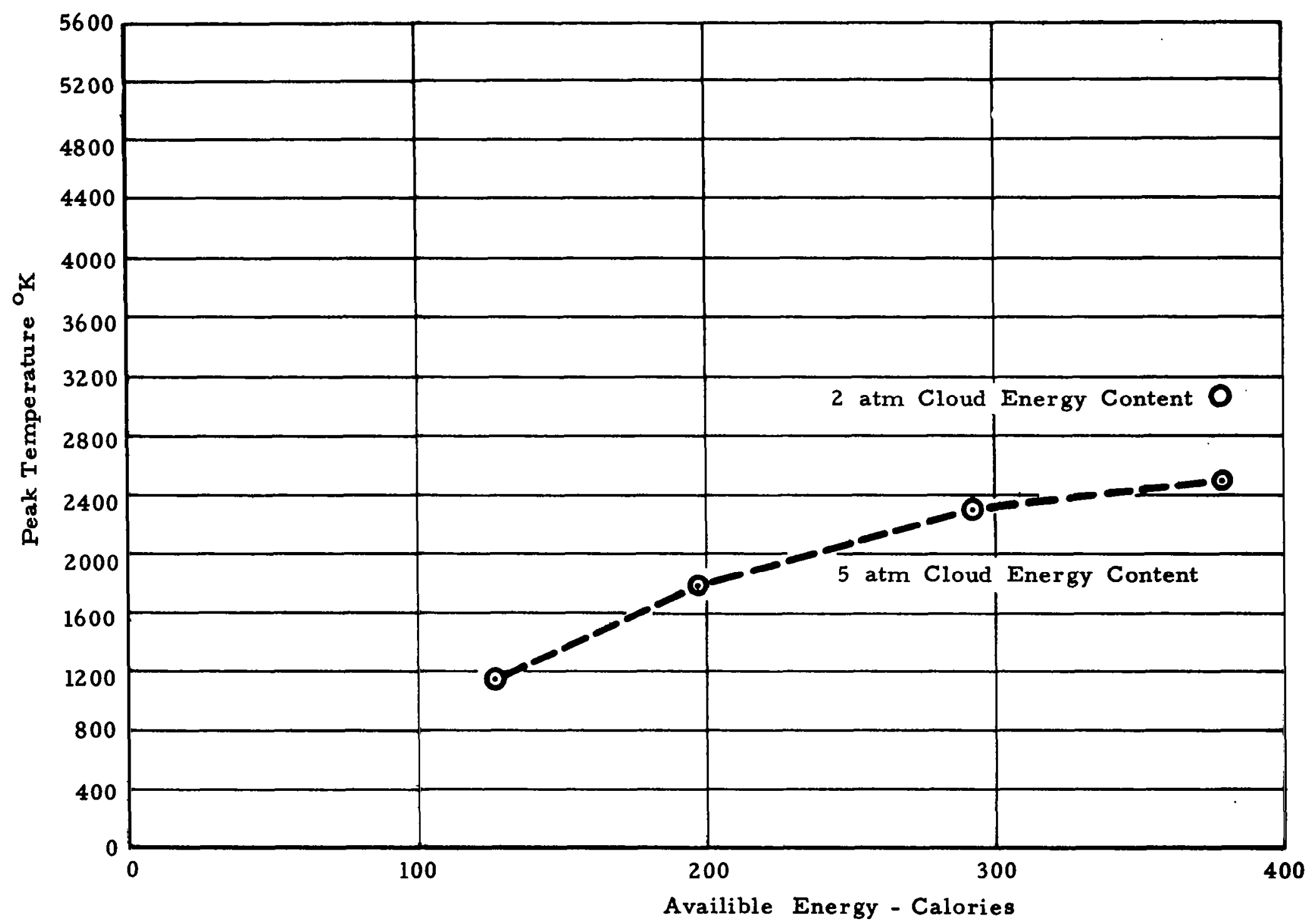

FIGURE 28 3mg CARBON IN HELIUM 
The remaining figures compare the observed energy absorption with the available radiant energy as a function of time. The total available energy was determined from graphite rod calorimetric measurements, and the distribution of this energy with time is determined from the silicon photodiode observation of the flashtube output. All of the figures represent the same flashtube operating point at $3.0 \mathrm{kv}$. A calculation was made of the energy input in each $0.1 \mathrm{msec}$ interval and then assuming a constant 50 percent absorption, the energy content of the gas was summed and plotted vs time. This constant 50 percent absorption case is used as a reference curve in Figures 29 through 34. The experimental points are found from the pressure rise vs time converted to temperature vs time on the assumption of a perfect gas. Multiplying by the (mass times specific heat) of gas and seed gave the energy content of the cloud. In the case of hydrogen where the specific heat varies appreciably with temperature (the value at $5000^{\circ} \mathrm{K}$ is five times the value at room temperature Reference 6) a rough numerical integration was hand calculated to give the energy content.

Figures 29, 30, and 31 show the cloud energy content vs time for $\mathrm{TaC}$, Fe and $C$ seeds in helium. The curves are seen to start at the same rate as the 50 percent absorption case but to fall progressively farther below the reference curve, to reach peaks and then start to fall while the energy content of a 50 percent absorption case is still rising.

Figures 32 through 34 show the same presentations for hydrogen. The same phenomenon occurs in each case, a peak is reached and the energy content of the cloud begins to fall while the energy content of a constant 50 percent absorption case is still rising. However, the hydrogen cases do approach the reference curve more closely than do the helium cases. Because of the higher specific heat of hydrogen both gas and seed temperatures rise more slowly than for comparable helium cases. Thus a greater amount of energy is deposited in a hydrogen cloud than in a helium cloud of the same temperature. Apparently at high temperatures either the absorption by the seed or transmission from seed to gas falls off significantly.

In Figure 7 and 8 the predicted gas temperatures vs time were plotted based on the radiant heating and conduction cooling calculation. The experimental points for similar cases are plotted on the same curves. Agreement is actually quite good for the hydrogen case, although the experimental absorption is initially at a somewhat higher rate than that calculated, so the cases are not entirely comparable. It is again clear that energy transfer to the gas decreased during heating giving an earlier peak and lower peak temperature than predicted. This discrepancy is much more obvious in the helium case where the $4200^{\circ} \mathrm{K}$ experimental peak is compared to the predicted $70000 \mathrm{~K}$ peak and again occurs early.

Examination of the gaseous and solid residues have not contributed appreciably to an understanding of the processes occurring. No gaseous reaction products were identified in helium cases and the hydrogen results gave trace amounts of high molecular weight products. The quantities obtained were much lower than expected and none of the anticipated $\mathrm{C}_{2} \mathrm{H}_{2}$ was detected. 


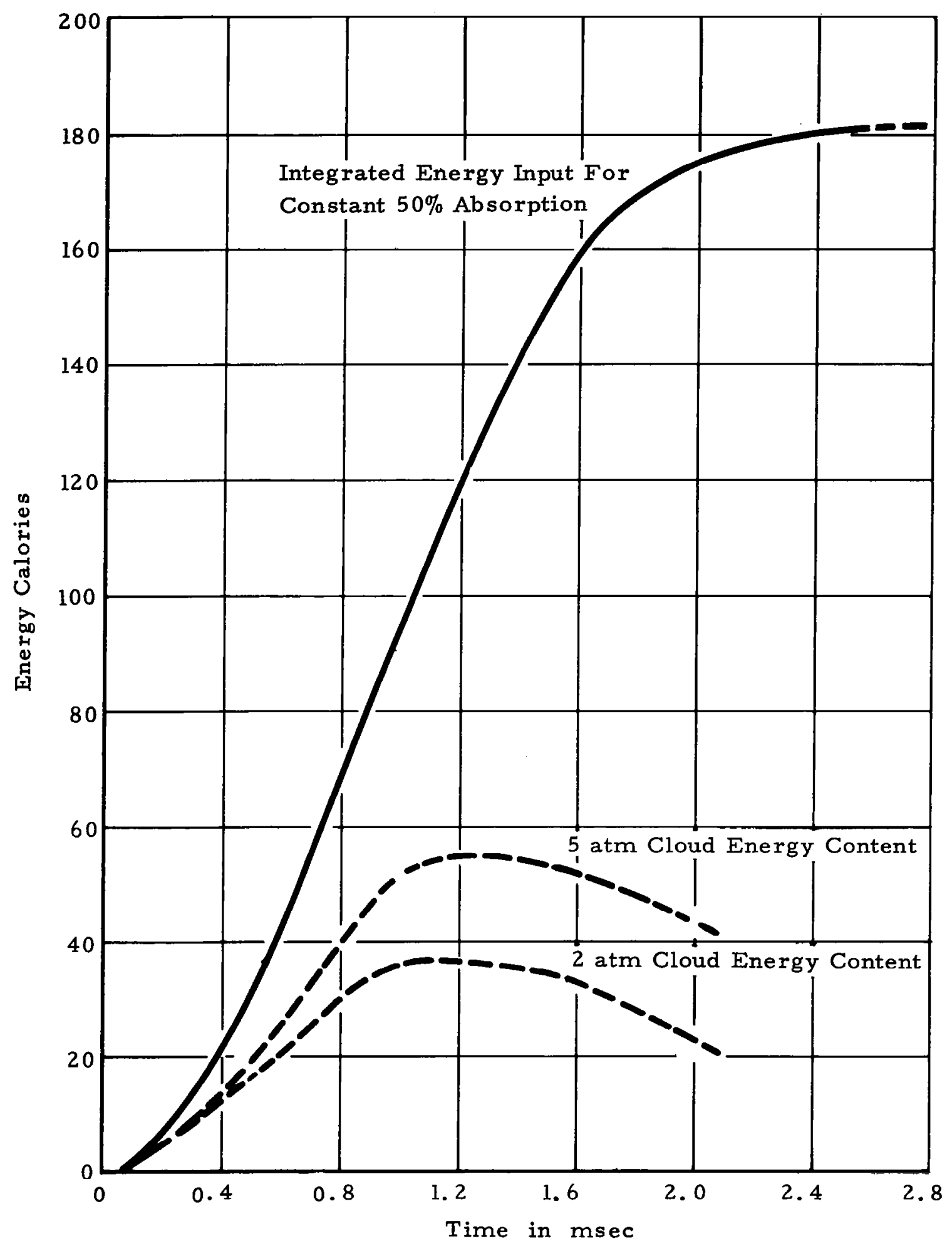

FIGURE 29 3Kv FLASH: TaC SEED IN HELIUM 


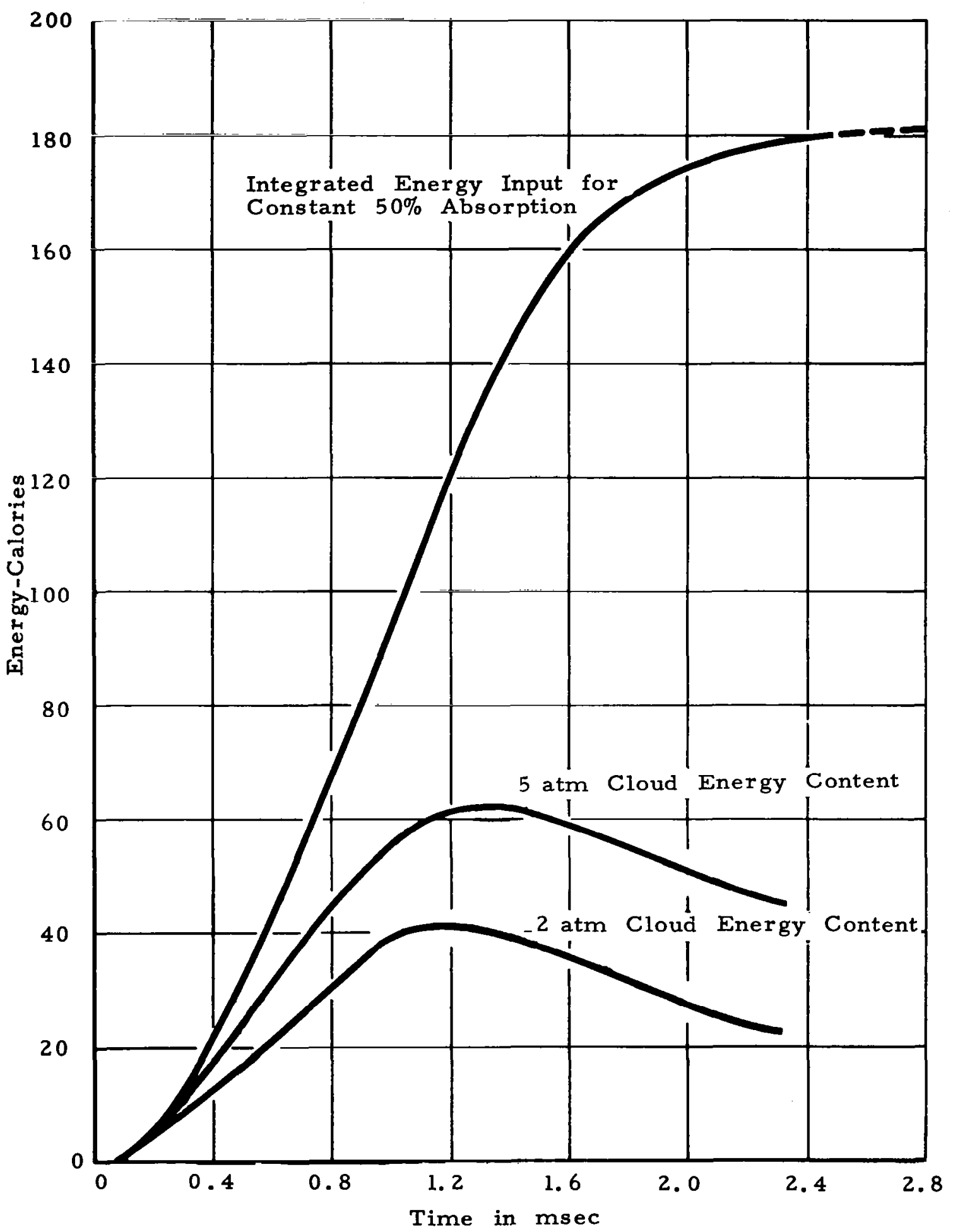

FIGURE 30 3Kv FLASH: Fe SEED IN HELIUM 


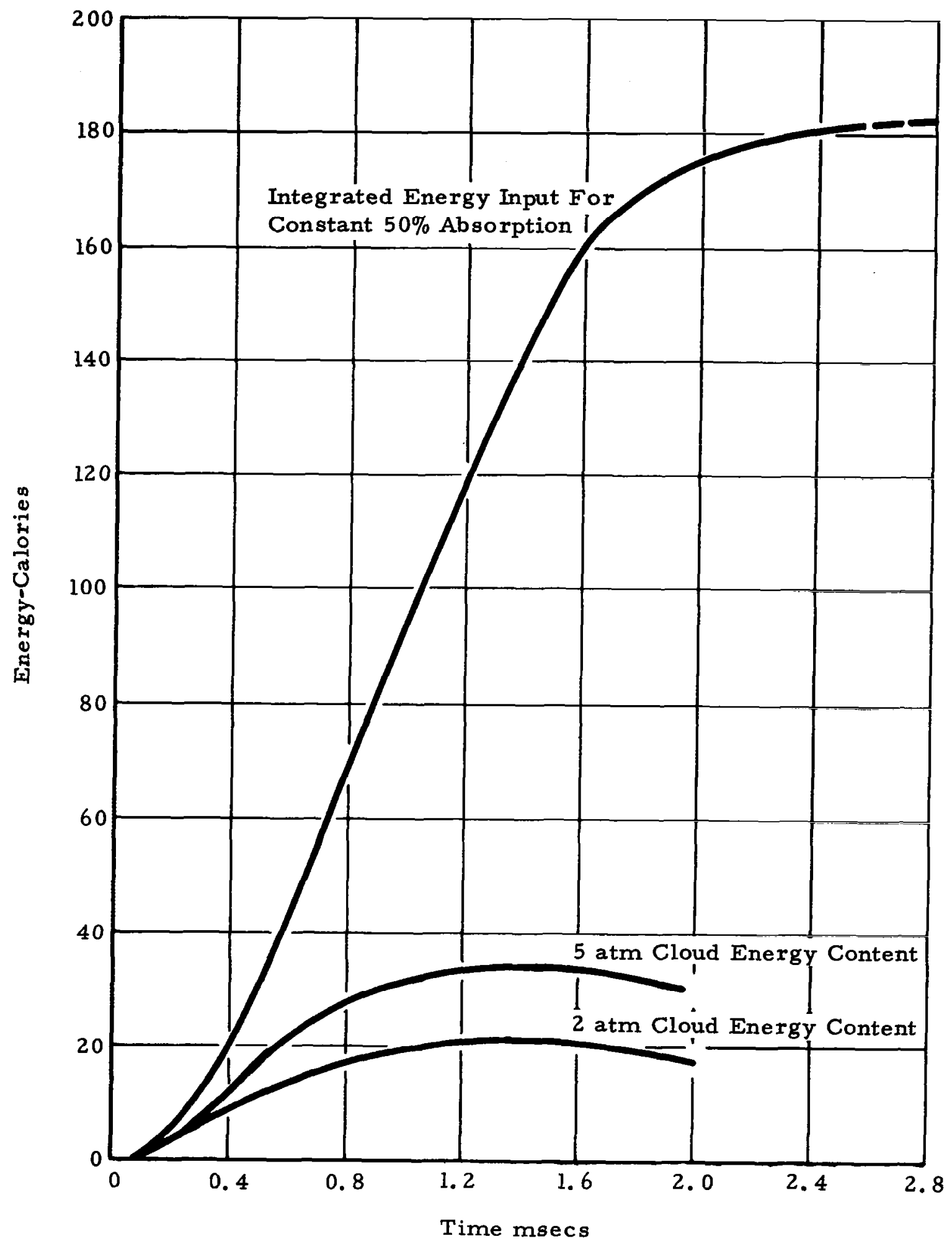

FIGURE 31 C SEED IN HELIUM 


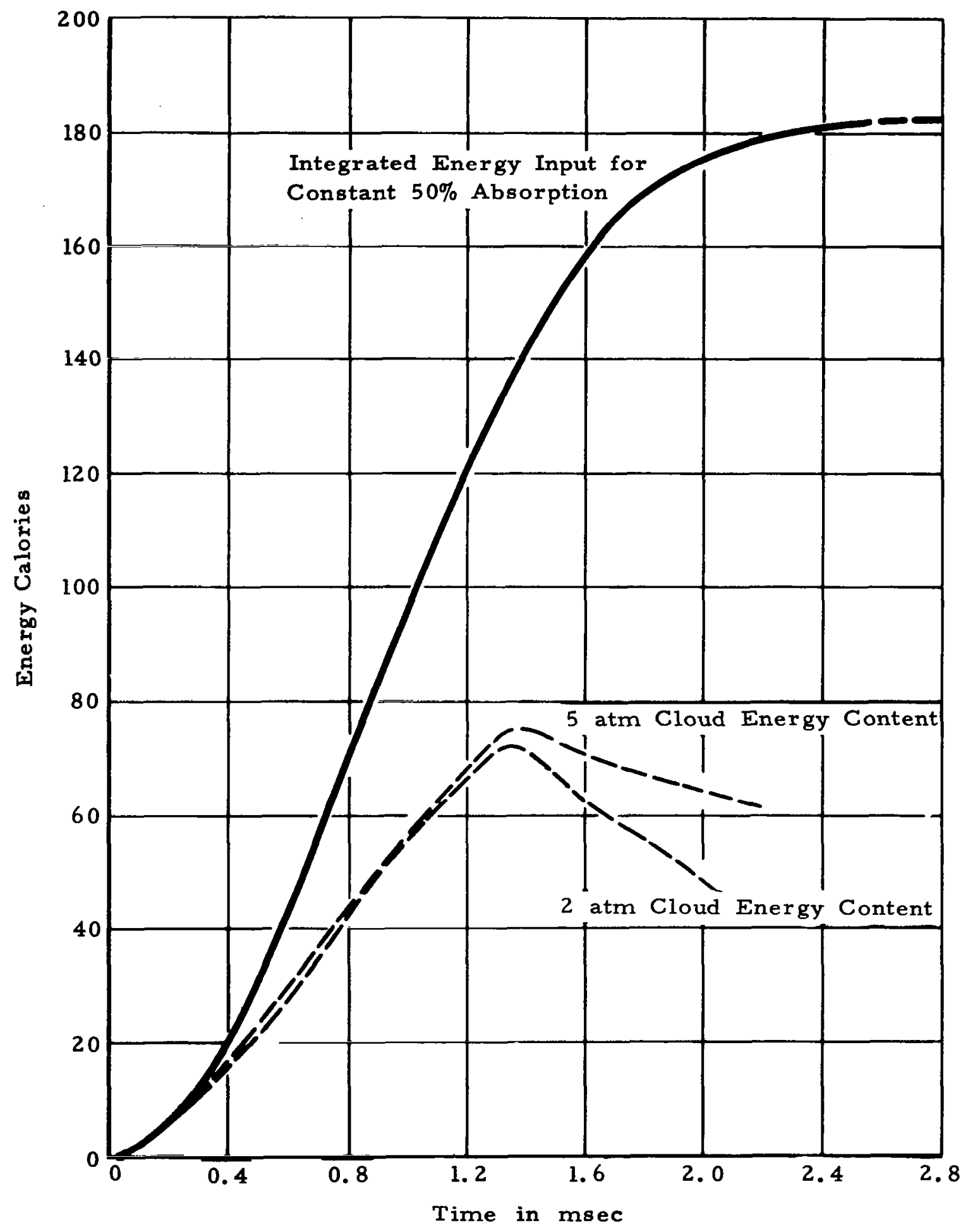

FIGURE 32 TaC SEED IN HYDROGEN 


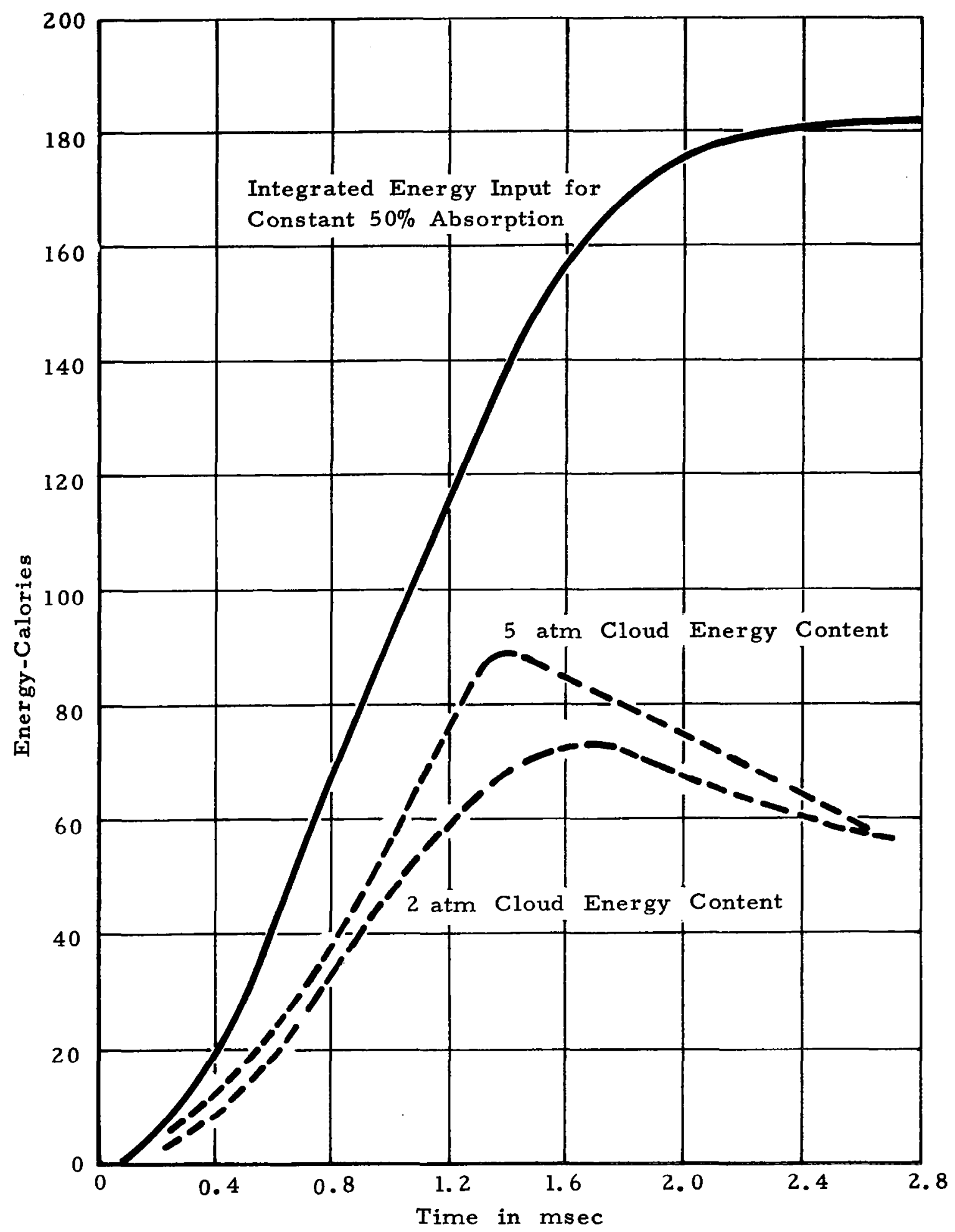

FIGURE 33 Fe SEED IN HYDROGEN 


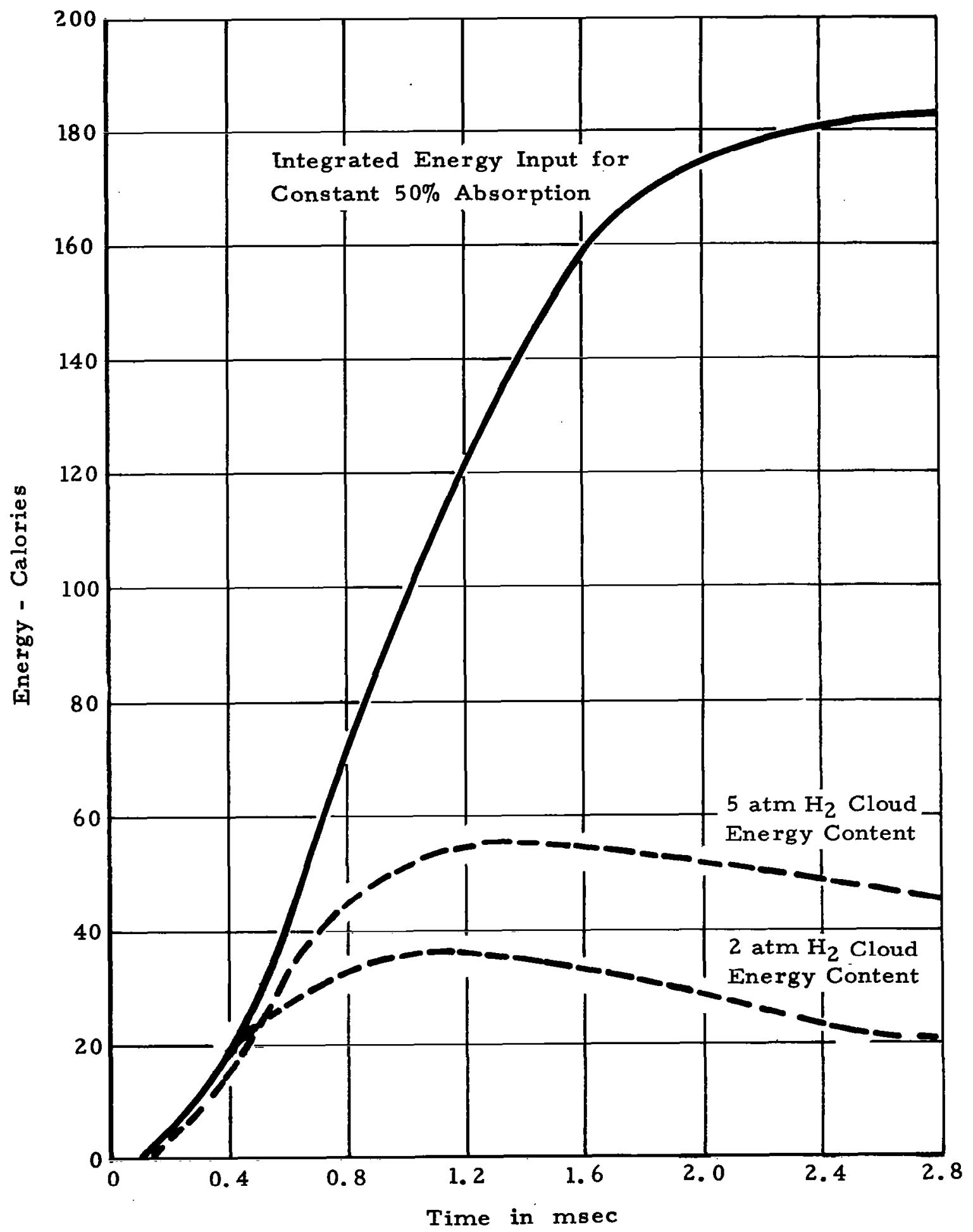

FIGURE 34 CARBON SEED IN HYDROGEN 
Examination of residual powders under an oil immersion microscope lens showed only minor differences from the original powders. The particle size distribution appeared similar except for agglomeration of carbon. There was evidence of melting in occasional large particles of $\mathrm{Fe}$ and $\mathrm{TaC}$; $\mathrm{i} . \mathrm{e.}$, large irregular particles or clusters were seen in the original and large spherical particles in the residual samples.

Spectroscopic and X-ray diffraction analysis of the residual powders failed to show evidence of chemical reactions except for a small amount of $\mathrm{Ta}_{2} \mathrm{O}_{5}$ for $\mathrm{TaC}$ in helium, which may have occurred from reduction of the quartz wall.

There are a number sources of uncertainty in these results, probably the largest of which is the amount of powder in the absorption cell in any particular case. Absorptions were generally found to be repeatable to \pm 10 percent for the same conditions of powder weight and gas pressure.

The pressure transducer was calibrated statically to 1000 psi within the accuracy of reading the oscilloscope screen. And pressure rises were measured from an oscilloscope screen with the same accuracy, +5 percent. Pressure rises were assumed to be due to temperature rises only. Evaporation of the seed material would cause some contribution to the measured pressure rise. But at $5 \mathrm{~atm}$ of gas in no case would this exceed 7 percent of the pressure. At 2 atm complete evaporation of the Fe seed could contribute 17 percent to the measured He pressure rise. All other cases evaporation would cause smaller errors. 


\section{CONCLUSIONS}

1. The results have shown that significant temperature rises can be obtained with the flash heating technique by radiant heating of seeded gases. There are, however, some difficulties for propulsion application; carbon, which would be the most desirable seed material because of its low density, is found to absorb energy at a lower rate than $\mathrm{Fe}$ and $\mathrm{TaC}$ even when cold absorption measurements indicated equal effectiveness. With the presently available energy it was not possible to raise either hydrogen or helium to temperatures of interest $\left(>4000^{\circ} \mathrm{K}\right)$ using a carbon seed, even though no significant evidence of carbon hydrogen reactions was observed.

2. Temperatures above $4000^{\circ} \mathrm{K}$ were obtained using Fe and TaC seed, particularly at 2 atmospheres of gas where the highest temperature (achieved with $\mathrm{TaC}$ in $2 \mathrm{~atm} \mathrm{He}$ and $3.5 \mathrm{kv}$ flash) was about $6000^{\circ} \mathrm{K}$. With the exception of the plateau noted in carbon/hydrogen, the peak temperature achieved continued to increase with increasing flash tube energy.

3. Energy balance considerations indicate more efficient utilization of available energy in hydrogen than in helium. This may be due to the relatively lower temperatures achieved in hydrogen. Perhaps more important is the decrease in energy absorption efficiency which was observed with increasing time in all cases (Figures 29 through 34 ) although no decrease in linear transmission was detected.

4. The major discrepancy between theory and experiment lies in the fact that observed peak temperatures are lower and occur earlier than predicted. There does not appear to be any way in which the parameters $a, r_{O}$, $\epsilon$ or $K$ can be changed which will simultaneously reduce the predicted peak and make it occur earlier. Only a decrease in energy flux to the seed appears capable of producing such a result. And yet optical transmission measurements through the cloud show no change during the flash. Three possible explanations are suggested; (a) an increase in energy absorption at the cell wall just compensates for decreased absorption in the cloud, (b) reflection and scattering by the seed material increase as absorption decreases giving an effect of constant transmission for optical measurements; and (c) particles remain generally the same, but at high temperatures energy is used for a chemical process rather than for gas heating.

No evidence of chemical changes has been found so that (a) and (b) are more likely explanations.

5. Further theoretical investigations should include a study of the effect of particle size distribution and of time-dependent parameters in the energy transfer process. 
Experimental information should be obtained about reflectivity vs absorptivity as a function of temperature for particles of the seed materials.

Extension of the flash heating experiments to higher energy is recommended to raise the temperature at which gas-solid dispersions can be observed. Measurements of flash heated samples with different radiant energy pulse shapes are also suggested to further characterize the observed decrease in energy absorption efficiency as a rate or energy dependent phenomenon. 


\section{REFERENCES}

1. Lanzo, Chester D. and Ragsdale, Robert G., NASA TND-1405, September 1962.

2. Lanzo, Chester D. and Ragsdale, Robert G., Proceedings of the 1964 Heat Transfer and Fluid Mechanics Institute, Warren $\mathrm{H}$. Hiedt and Salomon Levy, Editors; Stanford University Press, 1964.

3. Masser, Charles C., NASA TND-3197, January 1965.

4. McAlister, A.; Keng, Edward and Orr, Clyde, Jr., Heat Transfer to a Gas Containing a Cloud of Particles, Georgia Inst. Tech. , June 1965. Research Grant NsG-273-62 (Project A-635-002).

5. Grier, Normal T., NASA TND-1406, October, 1962.

6. Hronik, Richard H. ; Jones, Roger C., and Bronco, Charles J., Rev. Sci. Instr., Vol. 33, p. 776, 1962.

7. Schuldt, S. B., and Aagard, R. L., Applied Optics, Vol. 2, p. 509 1963.

8. Handbook of Chemistry and Physics, Chemical Rubber Publishing Co. , 1947.

9. Kuebler, N. A., and Nelson, L. S., Journal Opt. Soc. Am., Vol. 51, p. 1411,1961 .

10. Church, Charles H. ; Schlecht, Richard G.; Liberman, Irving and Swanson, Bruce W., AlAA Journal, Vol. 4, p. 1947, 1966. 